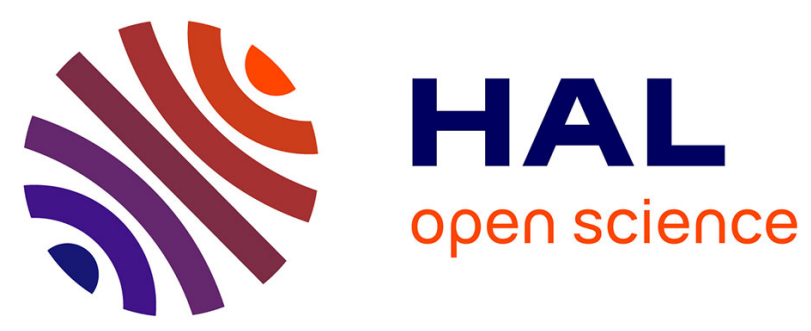

\title{
Synthesis and biological activities of 7-aza rebeccamycin analogues bearing the sugar moiety on the nitrogen of the pyridine ring.
}

\author{
Samir Messaoudi, Fabrice Anizon, P. Peixoto, M.H. David-Cordonnier, R. \\ Golsteyn, S. Leonce, Bruno Pfeiffer, Michelle Prudhomme
}

\section{To cite this version:}

Samir Messaoudi, Fabrice Anizon, P. Peixoto, M.H. David-Cordonnier, R. Golsteyn, et al.. Synthesis and biological activities of 7 -aza rebeccamycin analogues bearing the sugar moiety on the nitrogen of the pyridine ring.. Bioorganic and Medicinal Chemistry, 2006, 14, pp.7551-7562. 10.1016/j.bmc.2006.07.013 . hal-00119572

\section{HAL Id: hal-00119572 \\ https://hal.science/hal-00119572}

Submitted on 2 Mar 2007

HAL is a multi-disciplinary open access archive for the deposit and dissemination of scientific research documents, whether they are published or not. The documents may come from teaching and research institutions in France or abroad, or from public or private research centers.
L'archive ouverte pluridisciplinaire HAL, est destinée au dépôt et à la diffusion de documents scientifiques de niveau recherche, publiés ou non, émanant des établissements d'enseignement et de recherche français ou étrangers, des laboratoires publics ou privés. 


\title{
Synthesis and biological activities of 7-aza rebeccamycin analogues bearing the sugar moiety on the nitrogen of the pyridine ring
}

\author{
Samir Messaoudi, ${ }^{\mathrm{a}}$ Fabrice Anizon, ${ }^{\mathrm{a}}$ Paul Peixoto, ${ }^{\mathrm{b}}$ Marie-Hélène David-Cordonnier, ${ }^{\mathrm{b}}$ \\ Roy M. Golsteyn, ${ }^{\mathrm{c}}$ Stéphane Léonce, ${ }^{\mathrm{c}}$ Bruno Pfeiffer ${ }^{\mathrm{c}}$ and Michelle Prudhomme ${ }^{\mathrm{a}, *}$ \\ ${ }^{a}$ Université Blaise Pascal, Synthèse et Etude de Systèmes à Intérêt Biologique, UMR 6504 du CNRS, 63177 Aubière, France \\ ${ }^{\mathrm{b}}$ INSERM U814, Institut de Recherches sur le Cancer de Lille, Place de Verdun, 59045 Lille, France \\ ${ }^{\mathrm{c}}$ Institut de Recherches Servier, 125 Chemin de Ronde, 78290 Croissy-sur-Seine, France
}

Received 24 March 2006; revised 28 June 2006; accepted 3 July 2006

Available online 4 August 2006

\begin{abstract}
The synthesis of a new family of 7-aza-rebeccamycin analogues in which the sugar moiety is attached to the nitrogen of the pyridine ring is described. The capacity of the newly synthesized compounds to bind to DNA and to inhibit topoisomerase I has been evaluated. Their cytotoxicities toward four tumor cell lines, one murine leukemia L1210 and three human tumor cell lines, one prostate carcinoma DU145, one colon carcinoma HT29, and one non-small cell lung carcinoma A549, have been determined. Their abilities to inhibit the checkpoint kinase Chk1 have been evaluated.

(c) 2006 Elsevier Ltd. All rights reserved.
\end{abstract}

\section{Introduction}

Rebeccamycin and related compounds have triggered considerable interest in the past 15 years because of their ability to inhibit topoisomerase I, a nuclear enzyme essential for DNA replication and transcription. ${ }^{1-5}$ It has been shown that topoisomerase I is the major target for many rebeccamycin derivatives, however, various rebeccamycin analogues may have several other targets such as DNA or kinases. ${ }^{5}$ Recently, with the aim of improving the binding properties to their possible targets, new rebeccamycin analogues, in which one or both indole moieties have been replaced by a 7 -azaindole unit, have been synthesized. 6,7 In mono 7-azaindole compounds, the carbohydrate moiety has been linked either to the indole or to the azaindole (Fig. 1). The in vitro antiproliferative activities against a panel of nine tumor cell lines of these 7-aza-rebeccamycin have been determined. Compared to the parent compounds without 7 -azaindole unit, the aza-rebeccamycins were much more selective toward the tumor cell lines tested. The most sensitive cells were SK-N-MC neuroblastoma,

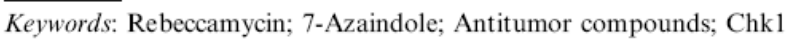
inhibitors; DNA binding agents; Topoisomerase I inhibitors.

* Corresponding author. Tel.: +334 734071 24; fax: +334 734077

17; e-mail: Michelle.PRUDHOMME@univ-bpclermont.fr
NCI-H69 small cell lung carcinoma, and A431 epidermoïd carcinoma cells with $\mathrm{IC}_{50}$ values in the nanomolar range. Interestingly, in spite of major differences in DNA binding and topoisomerase I inhibitory capacities between the compounds bearing the sugar moiety either on the indole or on the azaindole, in both series strong cytotoxicities were observed, suggesting other targets than DNA and topoisomerase I for compounds in which the sugar is attached to the azaindole. More recently, 7-aza-rebeccamycins bearing substituents on the aromatic framework, in various positions of the sugar part and on the imide nitrogen, have been synthesized. ${ }^{8}$

In the course of our syntheses of 7-aza-rebeccamycins, in the Mitsunobu coupling reaction carried out with aglycone $\mathbf{A}$, we observed the formation of a by-product which could not be purified by chromatography. It was isolated in mixture with triphenylphosphine oxide (Scheme 1). But because of the known tautomerization of 7 -azaindole, ${ }^{9,10}$ the formation of compound $\mathbf{1 0}$ with the carbohydrate attached to the nitrogen of the pyridine heterocycle was suspected. This compound could be of interest as an intermediate for the synthesis of a new family of 7 -aza-rebeccamycin analogues. The position of the sugar moiety may have major effects on DNA affinity and on topoisomerase I poisoning. 


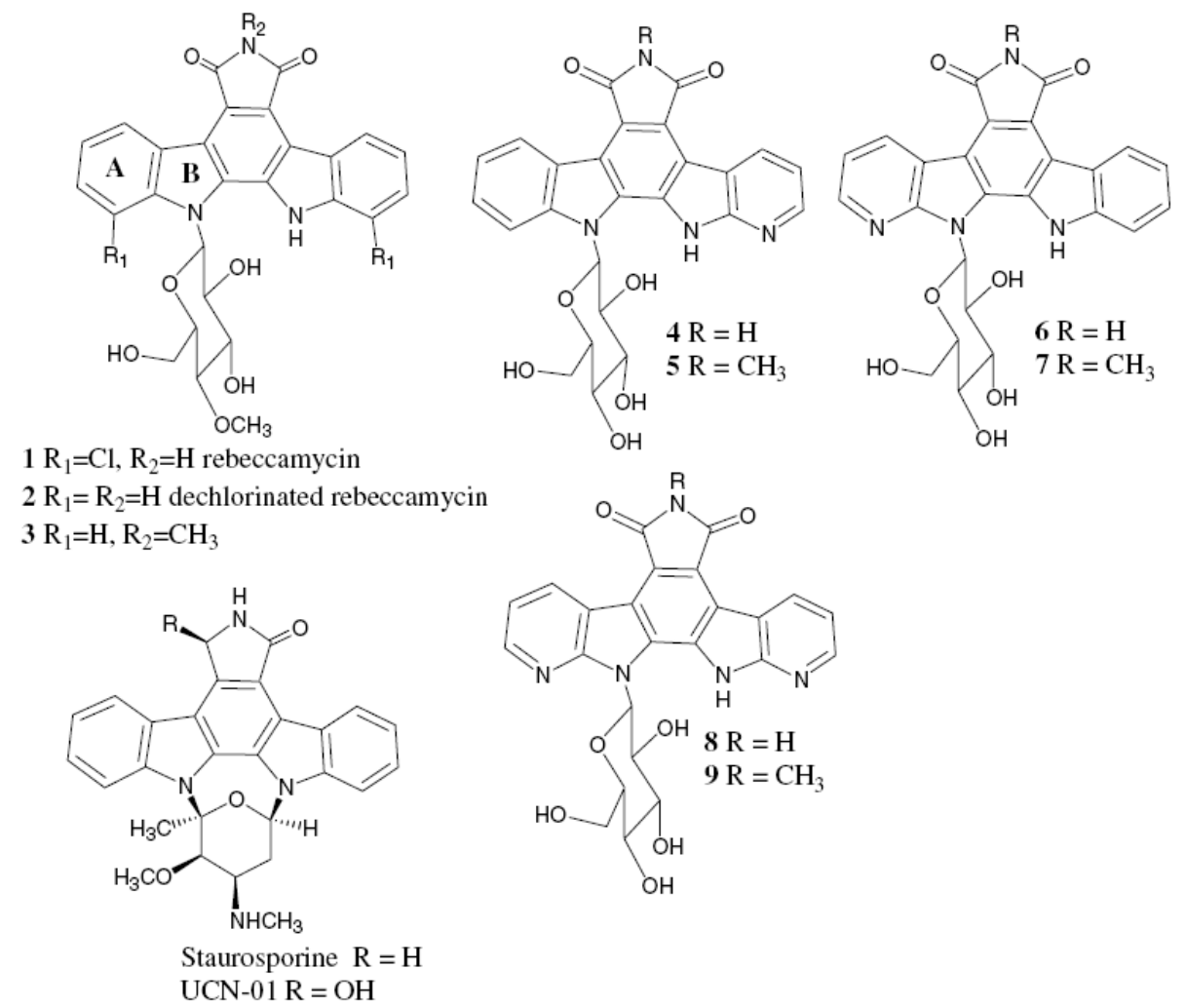

Figure 1. Structures of rebeccamycin and aza analogues previously synthesized.

In this paper, the syntheses of 7-aza-rebeccamycins bearing the sugar moiety on the pyridine ring are described. Their cytotoxicities against four tumor cell lines, their DNA binding properties, and their anti-topoisomerase I activities are reported. Moreover, since structurally related natural products staurosporine and UCN-01 (Fig. 1) are potent Checkpoint 1 kinase (Chk1) inhibitors, ${ }^{11}$ the capacities of the newly synthesized compounds to inhibit Chk1 have been investigated.

\section{Results and discussion}

\subsection{Chemistry}

The Mitsunobu reaction performed with aglycone $\mathbf{A}^{12}$ protected on the indole nitrogen with a Boc group and $\alpha$-D-2,3,4,6-tetra- $O$-acetyl-glucopyranose led to compound $\mathbf{B}$ as the major product (Scheme 1), whereas compound $\mathbf{1 0}$, the minor product, could only be isolated in mixture with triphenylphosphine oxide. Compound $\mathbf{1 0}$ was partly purified by flash chromatography. Removal of the Boc protective group was performed by reaction of compound $\mathbf{1 0}$ (in mixture with triphenylphosphine oxide) with formic acid giving compound 11. The position of the sugar moiety was assigned from NMR experiments $\left({ }^{1} \mathrm{H}-{ }^{1} \mathrm{H}\right.$ COSY and ${ }^{1} \mathrm{H}^{13}{ }^{13} \mathrm{C}$ correlations, INEPT-DN) (Scheme 2). The anomeric proton $\mathrm{H}_{1^{\prime}}$ at $7.01 \mathrm{ppm}$ is coupled with the two carbons at $125.7 \mathrm{ppm}(\mathrm{CH})$ and at $150.0 \mathrm{ppm}$ (C quat) of the 7-azaindole. An axial-axial coupling constant of $9 \mathrm{~Hz}$ between $\mathrm{H}_{1^{\prime}}$ and $\mathrm{H}_{2^{\prime}}$ is consistent with a $\beta$-coupling. Deprotection of the hydroxyl group of the sugar unit by aminolysis in methanol afforded compound $\mathbf{1 2}$. Oxidative photocyclization of $\mathbf{1 1}$, followed by the removal of the acetyl groups, led to $\mathbf{1 4}$, the first aza-rebeccamycin analogue of this series.

With the aim of introducing various substituents on the imide nitrogen, ${ }^{13} \mathrm{~N}$-methylated compound 12 was treated with aqueous $\mathrm{NaOH}$ followed by a work-up in an acidic medium affording $\mathbf{1 5}$ with concomitant hydrolysis of the acetates of the sugar moiety (Scheme 3). Like in $N$-methylated series, the Mitsunobu reaction carried out in $N$-benzyloxymethyl $(N$-BOM) series with aglycone $\mathrm{C}^{6}$ to obtain analogues without substituents on the imide nitrogen, either with 3,4,6-tri- $O$-benzyl-2-tosyl- $\alpha$-D-glucopyranose $\mathbf{D}^{14}$ or with $2,3,4,6$-tetra- $O$-benzyl- $\alpha$-D-glucopyranose $\mathbf{E}$, led to compounds $\mathbf{F}^{14}$ and $\mathbf{G}$, respectively, as the major products. The minor products of the reactions were $\mathbf{1 6}$ and $\mathbf{1 7}$ isolated in $17 \%$ and $25 \%$ yields, respectively (Scheme 4). Deprotection of the indole nitrogen with tetrabutylammonium fluoride ${ }^{15}$ gave compounds 18 and 19 which were further photocyclized leading to compounds 20 and 21. Removal of the BOM and benzyl protective groups, using boron tribromide then aqueous $\mathrm{NH}_{4} \mathrm{OH}$, yielded compounds 22 and 23 .

Via a Mitsunobu coupling reaction, compound $\mathbf{1 1}$ was isolated with only $8 \%$ yield. To enhance the coupling 


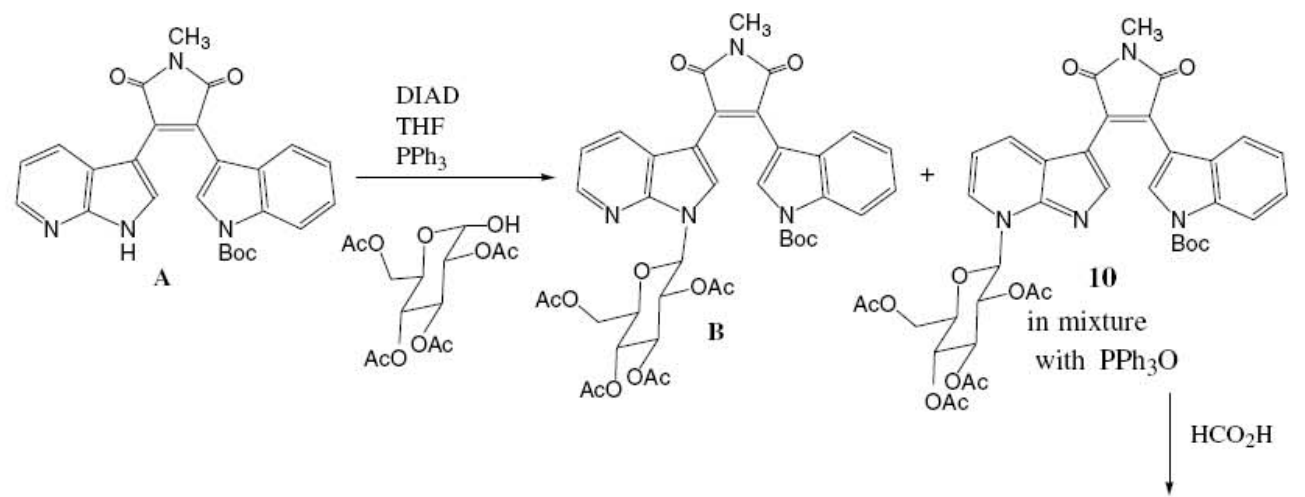<smiles>CN1C(=O)C(c2cnc3n(C(O)OC4C(O)C(O)C(O)C(O)C4O)cccc2-3)=C(c2c[nH]c3ccccc23)C1O</smiles>

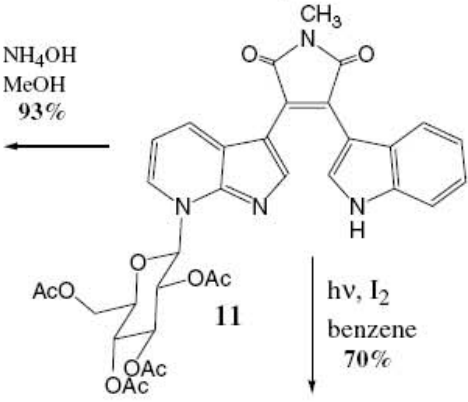<smiles>CN1C(=O)c2c(c3c4ccccc4[nH]c3c3nc4n(C(O)OC5C(O)C(O)C(O)C5O)cccc-4c23)C1O</smiles>

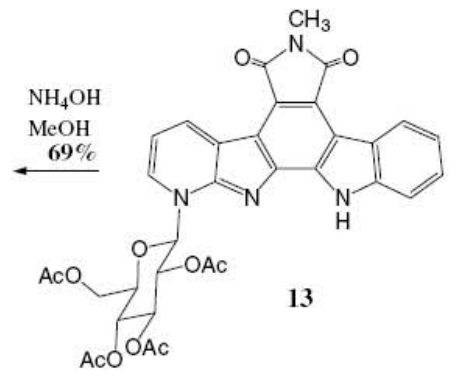

Scheme 1.

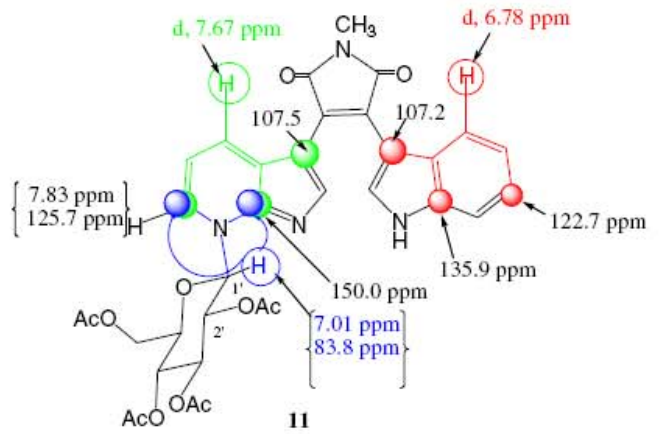

Scheme 2.

on the pyridine nitrogen, the reaction was carried out with aglycone $\mathbf{A}$ and a 1,2-anhydro sugar according to the method reported by Danishefsky et al. ${ }^{16}$ in a total synthesis of rebeccamycin (Scheme 5). The 3,4,6-tri- $O$ benzyl-1,2-anhydro sugar was prepared from 3,4,6-tri$O$-acetyl-glucal in three steps according to the literature procedure. ${ }^{17,18}$ After coupling of the carbohydrate then deprotection of the indole nitrogen using formic acid, compound $\mathbf{2 4}$ was obtained as the major product in $63 \%$ yield, whereas compound $\mathbf{F}$ was the minor product in only $20 \%$ yield. Photocyclization of $\mathbf{2 4}$ led to $\mathbf{2 5}$ in $69 \%$ yield.

\subsection{DNA binding}

As part of the determination of structure-activity relationships, compounds 14 and 22 were first tested for their ability to interact with DNA. Either calf thymus (CT-DNA) or poly $(\mathrm{dAdT})_{2}$ was used in melting temperature studies in the presence of increasing drug/base ratios of the derivatives $\mathbf{1 4}$ and $\mathbf{2 2}$. From comparison of the melting temperature $\left(T_{\mathrm{m}}\right)$ obtained in the presence or absence (control) of the tested drugs, Figure $2 \mathrm{~A}$ clearly evidences compound $\mathbf{1 4}$ as a potent DNA helix stabilizing molecule, whereas compound $\mathbf{2 2}$ clearly does not. The deduced $\Delta T_{\mathrm{m}}$ values obtained using increasing drug/DNA ratios of compound $\mathbf{1 4}$ in the presence of poly $(\mathrm{dAdT})_{2}$ are much higher (up to a $\Delta T_{\mathrm{m}}$ value of $10^{\circ} \mathrm{C}$ for $R=1$ ) than those obtained in the presence 


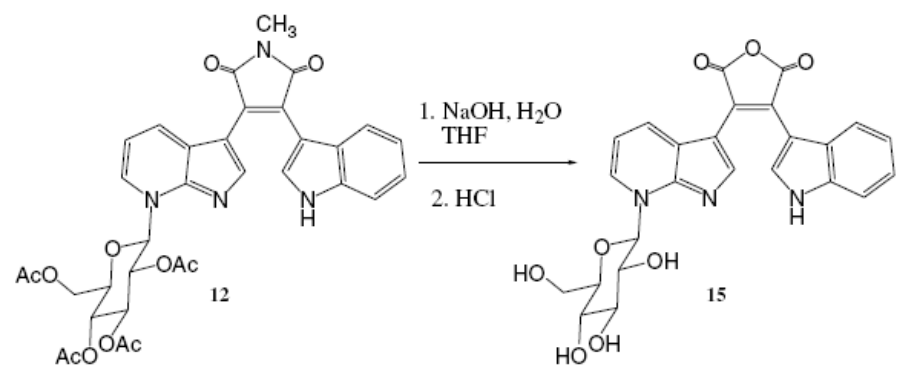

Scheme 3.

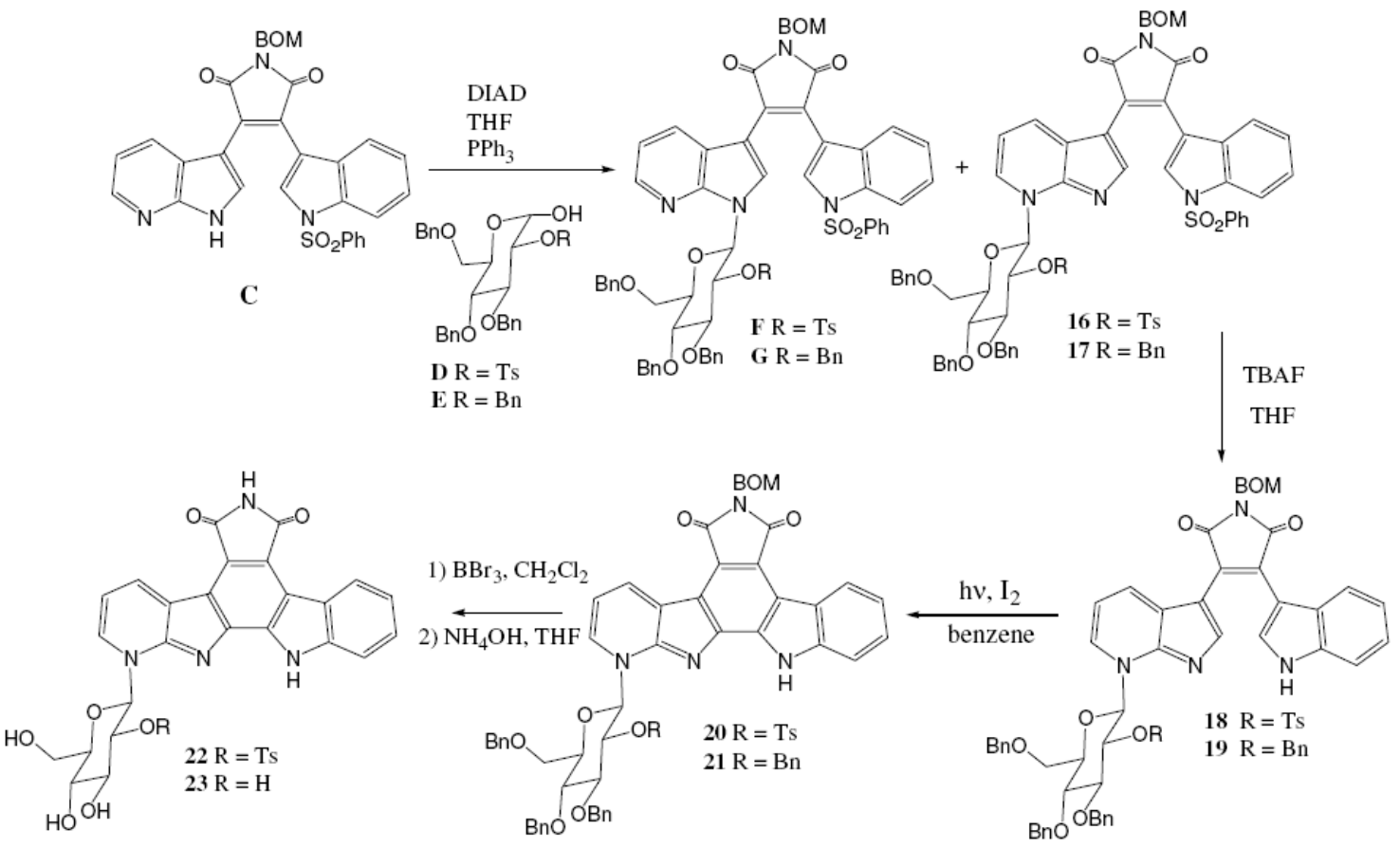

Scheme 4.

of CT-DNA ( $\Delta T_{\mathrm{m}}$ value of $4{ }^{\circ} \mathrm{C}$ for $\left.R=1\right)$. By contrast, the presence of a tosyl group on the sugar ring totally abolished this DNA binding propensity.

Interestingly, the presence of the sugar ring on the first ring (A-ring) of the rebeccamycin structure enhances the DNA binding propensity since the same structure but bearing the sugar ring on the classical B-ring (compound 7) failed to interact with DNA as previously shown. ${ }^{6}$

In order to get an insight into the nature of the DNA binding, we performed topoisomerase I induced gel relaxation experiments (Fig. 2B). Incubation of increasing concentrations of compound $\mathbf{1 4}$ correlates with an increase in the relaxation of the circular plasmid to a fully relaxed form and using a larger amount of compound to a positively supercoiled form typical of the effect of an intercalating compound. By contrast, compound 22 only weakly changes the DNA relaxation profile induced by topoisomerase I in correlation with its weak DNA binding efficiency.

\subsection{Topoisomerase I poisoning}

These selected rebeccamycin derivatives were further studied for their ability to poison topoisomerase I enzyme in order to address their mechanism of action. By comparison with the reference molecule camptothecin, increasing concentrations of compounds 14 or 22 were incubated with supercoiled DNA plasmid as described previously for Figure $2 \mathrm{~B}$ but the samples were separated on an ethidium bromide-containing agarose gel (Fig. 3A). An efficient DNA cleavage (Nck form) is only observed using camptothecin (CPT lane) suggesting that either $\mathbf{1 4}$ and $\mathbf{2 2}$ are not efficient topoisomerase poisons. An efficient gel shift of the supercoiled DNA form appears with increasing concentrations of $\mathbf{1 4}$ in 
<smiles>CN1C(=O)C(c2c[nH]c3ccccc23)=C(c2c[nH]c3ncccc23)C1=O</smiles>

A

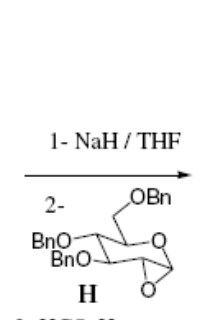

3- $\mathrm{HCO}_{2} \mathrm{H}$

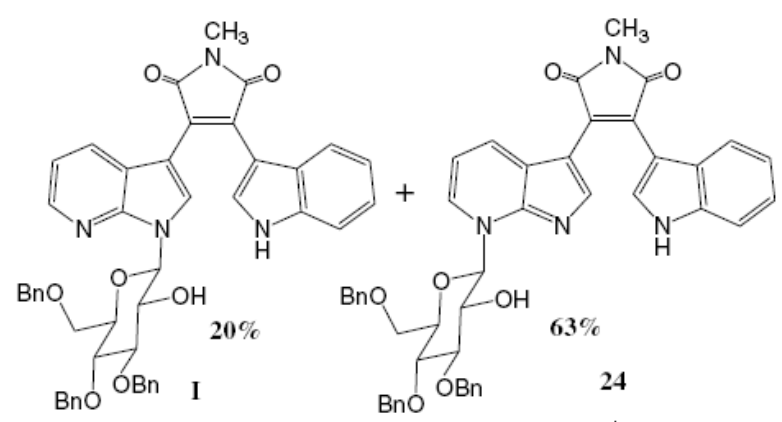

69\% $\mid \begin{aligned} & \mathrm{hv}, \mathrm{I}_{2} \\ & \text { benzene }\end{aligned}$

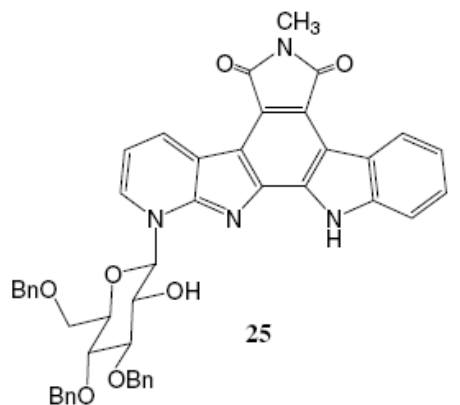

Scheme 5 .

correlation with its efficient DNA binding effect. Migration on a denaturing polyacrylamide gel of a radiolabeled DNA fragment incubated in the presence of increasing concentrations of $\mathbf{1 4}$ or $\mathbf{2 2}$ reveals that either compounds failed to poison topoisomerase I, only a weak cleavage site being observed using $50 \mu \mathrm{M}$ of compounds. By contrast, the control compound camptothecin and the topoisomerase I poisoning rebeccamycin derivative NB-506 used as controls efficiently induced cleavage sites (Fig. 3B).

\subsection{In vitro antiproliferative activities}

The in vitro antiproliferative activities toward four tumor cell lines: one murine leukemia L1210, and three human tumors: prostate carcinoma DU145, colon carcinoma HT29, and non-small cell lung carcinoma A549 were evaluated. The $\mathrm{IC}_{50}$ values in $\mu \mathrm{M}$ are reported in Table 1. Compared with the parent compounds 6 and 7 in which the sugar part is attached to the nitrogen of the B-ring, compounds 23 and $\mathbf{1 4}$ with the glucosyl moiety attached to the nitrogen of the A-ring were less cytotoxic against L1210 cells. Compound $\mathbf{1 4}$ is also less cytotoxic than compound 7 toward all the other tumor cell lines tested. At first sight, it seems that the shifting of the sugar unit from the B-ring to the A-ring decreases the cytotoxicity. Bis-indolyl compound $\mathbf{1 2}$ is less cytotoxic than the fully aromatized analogue 7. The presence of a tosyl group in the $2^{\prime}$ position of the sugar increases the cytotoxicity (compare 22 and 23), this effect could be due to a better penetration into the cells.

\subsection{Chk 1 inhibitory properties}

The transitions in the cell division cycle are regulated predominantly by the activities of cyclin-dependent kinases (CDKs). In the case of DNA damage, however, checkpoints are engaged and will block the cell cycle by eventually inhibiting CDKs to allow time for DNA repair. The activity of the G1/S phase checkpoint requires the p53 protein, which is either absent or mutated in more than $50 \%$ of human tumors. In the absence of a G1/S phase checkpoint, tumors become more dependent upon the G2/M phase checkpoint, which is regulated, in part, by Checkpoint 1 kinase (Chk1). An inhibitor of Chk1 should, therefore, selectively force cancer cells to bypass the G2 checkpoint and enter a premature and lethal mitosis. Staurosporine and UCN-01, isolated from cultures of Streptomyces, inhibit Chk1 with $\mathrm{IC}_{50}$ values of 8 and $7 \mathrm{nM}$, respectively. ${ }^{11}$ Clinical trials are currently undergoing combining UCN-01 with a DNA damaging agent such as cisplatin and topotecan. ${ }^{19}$ Compounds $\mathbf{1 4}, \mathbf{2 2}$, and $\mathbf{2 3}$ are carbazoles structurally related to the potent Chk1 inhibitors staurosporine and $\mathrm{UCN}-01$. Therefore, the inhibitory properties of compounds 14,22 , and 23 were determined and compared to that of rebeccamycin $\mathbf{1}$. The percentages of Chk 1 inhibition at a drug concentration of $10 \mu \mathrm{M}$ were evaluated, and for the most efficient inhibitor $\mathbf{2 3}$, the $\mathrm{IC}_{50}$ value was determined (Table 2). Rebeccamycin $\mathbf{1}$ and compounds $\mathbf{1 4}$ and $\mathbf{2 2}$ are weak Chk1 inhibitors, whereas compound $\mathbf{2 3}$ is a strong Chk1 inhibitor with an $\mathrm{IC}_{50}$ value toward this enzyme of $61 \mathrm{nM}$. Interestingly, Compound $\mathbf{2 3}$ with 
A

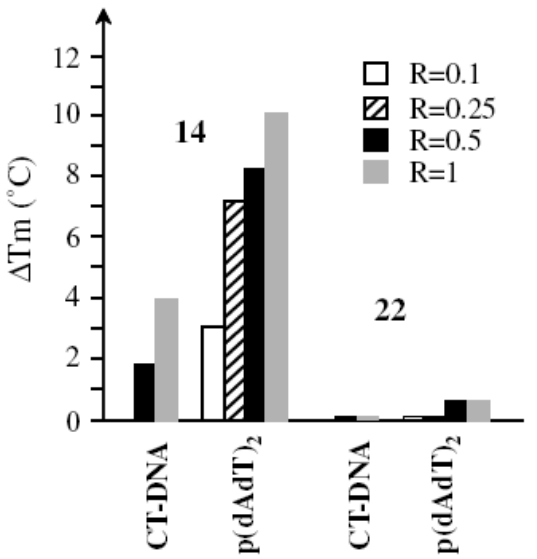

B

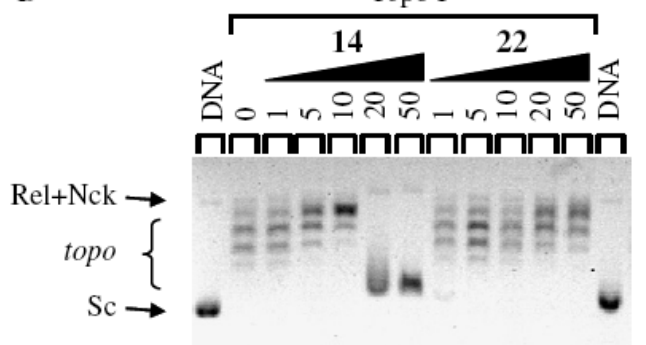

Figure 2. DNA binding efficiencies and mode of binding to the DNA helix of compounds 14 and 22. (A) Melting temperature studies were performed using either calf thymus DNA or a synthetic poly $(\mathrm{dAdT})_{2}$ double stranded oligonucleotide and increasing concentrations of 14 or 22 to a drug/DNA ratio $R$ of 0.1 (white boxes), 0.25 (dashed boxes), 0.5 (black boxes) or 1 (gray boxes). The various $T_{\mathrm{m}}$ values were deduced from the first derivative plots and were subtracted from the value obtained using either DNA alone to obtain the various $\Delta T_{\mathrm{m}}$ values presented in the diagrams. (B) Topoisomerase I DNA relaxation studies were obtained by incubating supercoiled plasmid DNA with increasing concentrations of compounds $\mathbf{1 4}$ or $\mathbf{2 2}$ prior to the addition of topoisomerase I enzyme as described in the experimental section. The DNA samples were then separated on an agarose gel and stained post-electrophoresis using ethidium bromide. Sc, Rel, Nck, and topo refer to supercoiled, relaxed, nicked, and topoisomer DNA plasmid forms, respectively. Lanes DNA refer to the native plasmid DNA alone.

the glucosyl moiety attached to the nitrogen of the pyridine ring is a considerably stronger Chk 1 inhibitor than the parent compound $\mathbf{6}$ in which the sugar is linked to the nitrogen of the pyrrole. Concerning compound 22, it may be possible that the bulky tosyl group of compound 22 prevents the binding to the ATP binding site of the enzyme. The weak inhibitory effect of compound $\mathbf{1 4}$ is not surprising since the imide nitrogen is not free. In the crystal structures of Chk1 in complex with staurosporine, UCN-01, and isogranulatimide, a natural product with a carbazole structure containing an imide upper heterocycle, two hydrogen bonds are conserved: one between a carbonyl of the upper heterocycle of the drugs and the $\mathrm{Cys}^{87}$ residue, the other between the lactam or imide NH and the $\mathrm{Glu}^{85}$ residue. ${ }^{11,20}$ The $N$-methylated imide prevents the stabilization of compound $\mathbf{1 4}$ inside the ATP binding site of Chk1.
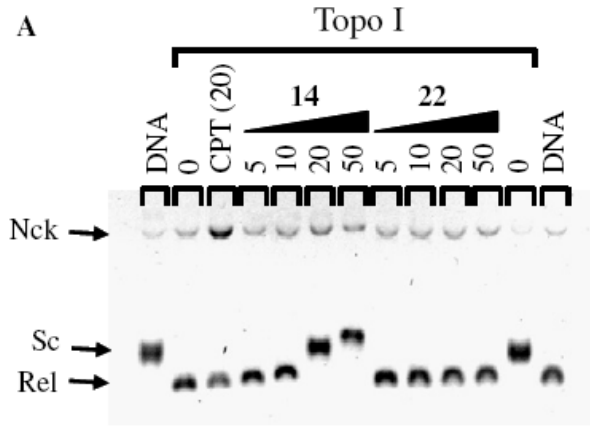

B

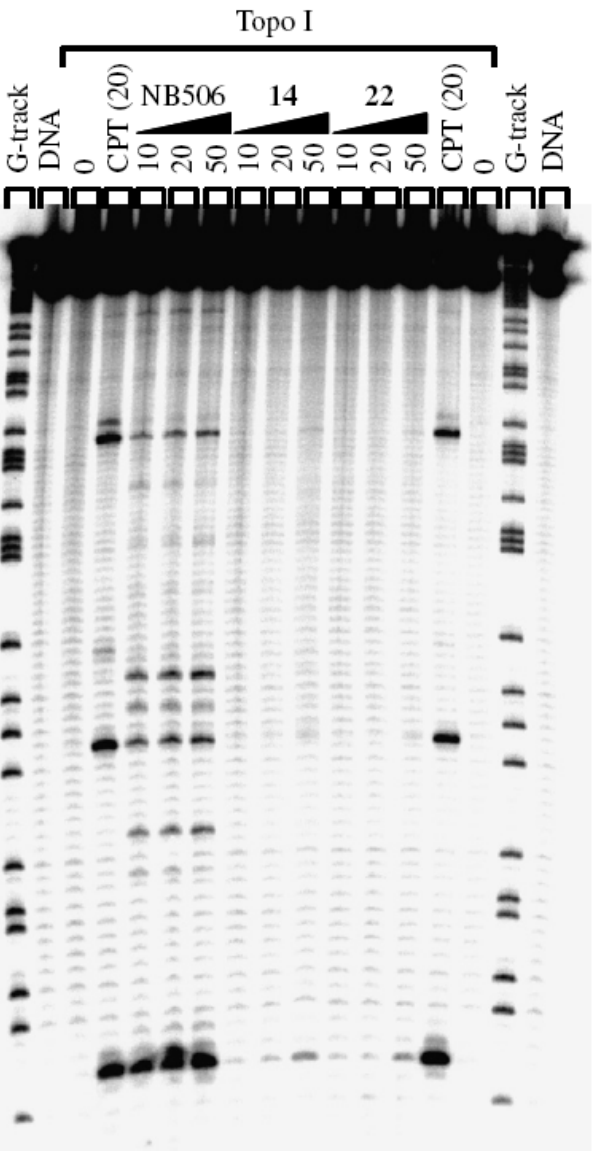

Figure 3. Topoisomerase I DNA poisoning. Increasing concentrations of 14, 22, NB506 or $20 \mu \mathrm{M}$ of CPT were incubated with supercoiled pUC19 plasmid DNA (A) or the 117 bp radiolabeled DNA fragment (B) prior to further addition of $4 \mathrm{U}$ of human recombinant topoisomerase I enzyme. The DNA samples were then separated on a $1 \%$ agarose ethidium bromide-containing gel (A) or a $8 \%$ denaturing polyacrylamide gel (B). Sc, Rel, and Nck refer to supercoiled, relaxed, and nicked DNA plasmid forms, respectively. G-track lanes reveal the guanines position on the radiolabeled 117 bp DNA fragment. Lanes DNA correspond to the relative DNA alone.

\section{Conclusion}

In conclusion, we have prepared a novel series of aza rebeccamycin derivatives in which the glucosyl moiety is attached to the nitrogen of the pyridine ring. It appeared that the shifting of the sugar from the nitrogen 
Table 1. In vitro antiproliferative activities $\left(\mathrm{IC}_{50} \mu \mathrm{M}\right)$ toward several tumor cell lines: one murine leukemia L1210, and four human tumors prostate carcinoma DU145, colon carcinoma HT29, non-small cell lung carcinoma A549, and colon carcinoma HCT116

\begin{tabular}{llllll}
\hline Compound & L1210 & DU145 & HT29 & A549 & HCT116 \\
\hline $\mathbf{1}$ & 0.14 & ne & 0.3 & 0.3 & nd \\
$\mathbf{2}$ & 0.11 & ne & 2.5 & 2 & nd \\
$\mathbf{3}$ & 0.58 & 0.42 & 0.43 & 0.46 & nd \\
$\mathbf{4}$ & 0.06 & 0.59 & 4.8 & 5.3 & nd \\
$\mathbf{5}$ & 1.3 & 6 & 17.8 & 47.2 & nd \\
$\mathbf{6}$ & 0.13 & 0.36 & $>100$ & $>100$ & nd \\
$\mathbf{7}$ & 0.34 & 0.20 & 67.2 & 59.9 & nd \\
$\mathbf{1 2}$ & 85 & 82.6 & 76.2 & $>100$ & nd \\
$\mathbf{1 4}$ & 17.6 & 83 & $>100$ & $>100$ & nd \\
$\mathbf{2 2}$ & 15.4 & nd & 57.9 & nd & 13.4 \\
$\mathbf{2 3}$ & 48 & nd & 100 & nd & 16 \\
\hline
\end{tabular}

Table 2. Percentages of Chk1 inhibition at a drug concentration of $10 \mu \mathrm{M}$

\begin{tabular}{cll}
\hline Compound & $\%$ of Chk1 inhibition at $10 \mu \mathrm{M}$ & $\mathrm{IC}_{50}$ in $\mu \mathrm{M}$ \\
\hline $\mathbf{1}$ & 62 & nd \\
$\mathbf{6}$ & 15 & nd \\
$\mathbf{1 4}$ & 31.8 & nd \\
$\mathbf{2 2}$ & 45.5 & nd \\
$\mathbf{2 3}$ & 85 & 0.061 \\
\hline
\end{tabular}

of the B-ring to the nitrogen of the A-ring enhances binding to the DNA. However, as observed with other rebeccamycin derivatives, the DNA binding affinity is not correlated with topoisomerase I inhibitory properties. The shifting of the sugar from the nitrogen of the B-ring to the nitrogen of the A-ring considerably increases the Chk1 inhibitory effect. Indeed, compound $\mathbf{2 3}$ is a potent Chk1 inhibitor. The work reported here provides a new avenue to the design of Chk1 inhibitors.

\section{Experimental}

\subsection{Chemistry}

IR spectra were recorded on a Perkin-Elmer 881 spectrometer. NMR spectra were recorded on a Bruker AVANCE $400 \quad\left({ }^{1} \mathrm{H}: \quad 400 \mathrm{MHz},{ }^{13} \mathrm{C}\right.$ : $100 \mathrm{MHz}$ ) chemical shifts $\delta$ in ppm, the following abbreviations are used: singlet (s), doublet (d), triplet $(\mathrm{t})$, pseudo-triplet $(\mathrm{pt})$, doubled triplet $(\mathrm{dt})$, multiplet (m), br s (broad signal), tertiary carbons (C tert), and quaternary carbons ( $\mathrm{C}$ quat). The signals were assigned from ${ }^{1} \mathrm{H}-{ }^{1} \mathrm{H}$ COSY and ${ }^{13} \mathrm{C}-{ }^{1} \mathrm{H}$ correlations. Low resolution mass spectra (ESI+ and $\mathrm{APCI}+$ ) were determined on a MS Hewlett Packard engine. HRMS spectra $(\mathrm{FAB}+)$ were determined on a high resolution Fisons Autospec-Q spectrometer at CESAMO (Talence, France). Chromatographic purifications were performed by flash silicagel Geduran SI 60 (Merck) $0.040-0.063 \mathrm{~mm}$ or Kieselgel 60 (Merck) $0.063-0.200 \mathrm{~mm}$ column chromatography. For purity tests, TLC were performed on fluorescent silica gel plates (60 $\mathrm{F}_{254}$ from Merck).
4.1.1. 3-(1 $\mathrm{H}$-Indol-3-yl)-1-methyl-4-[7-(2,3,4,6-tetra- $O$ acetyl-p-D-glucopyranos-1-yl)-7 $\boldsymbol{H}$-pyrrolo[2,3-b|pyridin-3yll-pyrrole-2,5-dione (11). To a solution of aglycone A $(384 \mathrm{mg}, 0.863 \mathrm{mmol})$ in THF $(27 \mathrm{~mL})$ were added $2,3,4,6-O$-acetyl- $\alpha$-D-glucopyranose $(672 \mathrm{mg}, 1.93 \mathrm{mmol}$ ) and triphenylphosphine $(505 \mathrm{mg}, 1.93 \mathrm{mmol}$ ). The mixture was cooled to $-78^{\circ} \mathrm{C}$ then diethyl azodicarboxylate (DEAD) $(304 \mu \mathrm{L}, 1.93 \mathrm{mmol})$ was added dropwise. The mixture was allowed to reach room temperature, then was stirred at room temperature for $18 \mathrm{~h}$. Water $(50 \mathrm{~mL})$ was added. After extraction with EtOAc, the organic phase was dried over $\mathrm{MgSO}_{4}$, and the solvent was removed. The residue was purified by flash chromatography (eluent: cyclohexane/AcOEt 7:3 containing $\mathrm{NEt}_{3} 20 \%$ ) to give a mixture of $N$-Boc 10 and triphenylphosphine oxide $(600 \mathrm{mg})$.

This mixture was dissolved in formic acid $(250 \mathrm{~mL})$ and stirred at room temperature for $24 \mathrm{~h}$. After evaporation, the residue was purified by flash chromatography (eluent: cyclohexane/AcOEt from 7:3 to 5:5) to give 11 (48 mg, $0.071 \mathrm{mmol}, 8 \%$ yield) as a red solid.

Mp: $155^{\circ} \mathrm{C}$. IR (KBr) $v_{\mathrm{C}=\mathrm{O}} 1700,1752 \mathrm{~cm}^{-1}, v_{\mathrm{NH}} 3300$ $3500 \mathrm{~cm}^{-1}$. HRMS (ESI+) $[\mathrm{M}+\mathrm{H}]^{+}$calcd for $\mathrm{C}_{34} \mathrm{H}_{33} \mathrm{~N}_{4} \mathrm{O}_{11}$ 673.2146, found 673.2118 . ${ }^{1} \mathrm{H}$ NMR $\left(400 \mathrm{MHz}, \mathrm{CDCl}_{3}\right): 1.62\left(3 \mathrm{H}, \mathrm{s}, \mathrm{CH}_{3} \mathrm{CO}\right), 2.01(3 \mathrm{H}, \mathrm{s}$, $\left.\mathrm{CH}_{3} \mathrm{CO}\right), 2.08\left(6 \mathrm{H}, \mathrm{s}, \mathrm{CH}_{3} \mathrm{CO}\right), 3.19\left(3 \mathrm{H}, \mathrm{s}, \mathrm{N}-\mathrm{CH}_{3}\right)$, $4.11-4.20\left(2 \mathrm{H}, \mathrm{m}, \mathrm{H}_{5^{\prime}}, \mathrm{H}_{6^{\prime}}\right), 4.34\left(1 \mathrm{H}, \mathrm{dd}, J_{1}=13.0\right.$ $\left.\mathrm{Hz}, J_{2}=5.0 \mathrm{~Hz}, \mathrm{H}_{6^{\prime}}\right), 5.27\left(1 \mathrm{H}, \mathrm{t}, J=10.0 \mathrm{~Hz}, \mathrm{H}_{4^{\prime}}\right)$, $5.37\left(1 \mathrm{H}, \mathrm{t}, J=10.0 \mathrm{~Hz}, \mathrm{H}_{2^{\prime}}\right), 5.58(1 \mathrm{H}, \mathrm{t}, J=9.5 \mathrm{~Hz}$, $\left.\mathrm{H}_{3^{\prime}}\right), 6.646 .72(2 \mathrm{H}, \mathrm{m}), 6.78(1 \mathrm{H}, \mathrm{d}, J=8.0 \mathrm{~Hz}), 7.01$ $\left(1 \mathrm{H}, \mathrm{d}, J=9.0 \mathrm{~Hz}, \mathrm{H}_{1^{\prime}}\right), 7.05(1 \mathrm{H}, \mathrm{t}, J=7.5 \mathrm{~Hz}), 7.34$ $(1 \mathrm{H}, \mathrm{d}, J=8.0 \mathrm{~Hz}), 7.67(1 \mathrm{H}, \mathrm{d}, J=8.0 \mathrm{~Hz}), 7.79-7.84$ $(2 \mathrm{H}, \mathrm{m}), 8.38(1 \mathrm{H}, \mathrm{s}), 8.82\left(1 \mathrm{H}, \mathrm{s}, \mathrm{NH}_{\text {ind }}\right) .{ }^{13} \mathrm{C} \mathrm{NMR}$ $\left(100 \mathrm{MHz}, \mathrm{CDCl}_{3}\right)$ : 20.0, 20.5, 20.6, $20.7\left(\mathrm{CH}_{3} \mathrm{CO}\right)$, $24.2\left(\mathrm{~N}-\mathrm{CH}_{3}\right), 61.6\left(\mathrm{C}_{6^{\prime}}\right), 67.9,71.6,72.5,75.5\left(\mathrm{C}_{2^{\prime}}\right.$, $\left.\mathrm{C}_{3^{\prime}}, \mathrm{C}_{4^{\prime}}, \mathrm{C}_{5^{\prime}}\right), 83.8\left(\mathrm{C}_{1^{\prime}}\right), 111.0,111.4,120.4,121.7$, $122.7,125.7,127.9,134.7,149.9$ (C tert arom), 107.2, $107.5,124.9,125.1,127.9,128.5,136.0,150.0$ (C quat arom), 169.0, $169.6(2 \mathrm{C}), 170.5,172.6(2 \mathrm{C})(\mathrm{C}=\mathrm{O})$.

4.1.2. 3-(1H-Indol-3-yl)-1-methyl-4-[(7- $\beta$-D-glucopyranos1-yl)-7H-pyrrolo[2,3-b]pyridin-3-yll-pyrrole-2,5-dione (12). To a solution of $11(20 \mathrm{mg}, 0.0297 \mathrm{mmol})$ in methanol $(10 \mathrm{~mL})$ was added $28 \%$ aqueous $\mathrm{NH}_{4} \mathrm{OH}(16 \mathrm{~mL})$. The mixture was stirred at $65^{\circ} \mathrm{C}$ for $22 \mathrm{~h}$. The solvent was removed, then water and EtOAc were added to the residue. After extraction with EtOAc, the organic phase was dried over $\mathrm{MgSO}_{4}$, and the solvent was removed to give 12 (14 mg, $0.0277 \mathrm{mmol}, 93 \%$ yield) as a red solid.

Mp: $182-185^{\circ} \mathrm{C}$. IR (KBr) $v_{\mathrm{C}=\mathrm{O}} 1695,1750 \mathrm{~cm}^{-1}$, $v_{\mathrm{NH}, \mathrm{OH}} 3100-3600 \mathrm{~cm}^{-1}$. HRMS (FAB + ) $[\mathrm{M}+\mathrm{H}]^{+}$calcd for $\mathrm{C}_{26} \mathrm{H}_{24} \mathrm{~N}_{4} \mathrm{O}_{7} 505.1723$, found 505.1719. ${ }^{1} \mathrm{H}$ NMR $\left(400 \mathrm{MHz}\right.$, DMSO- $\left.d_{6}\right): 3.07\left(3 \mathrm{H}, \mathrm{s}, \mathrm{CH}_{3}\right), 3.48-3.56$ $(4 \mathrm{H}, \mathrm{m}), 3.72-3.85(2 \mathrm{H}, \mathrm{m}), 4.68(1 \mathrm{H}, \mathrm{t}, J=6.0 \mathrm{~Hz}$, $\mathrm{OH}), 5.25(1 \mathrm{H}, \mathrm{d}, J=4.5 \mathrm{~Hz}, \mathrm{OH}), 5.39(2 \mathrm{H}, \mathrm{d}$, $J=5.5 \mathrm{~Hz}, \mathrm{OH}), 6.53(1 \mathrm{H}, \mathrm{d}, J=8.5 \mathrm{~Hz}), 6.71(1 \mathrm{H}, \mathrm{d}$, $J=7.0 \mathrm{~Hz}), 6.77(1 \mathrm{H}, \mathrm{d}, J=8.0 \mathrm{~Hz}), 6.87(1 \mathrm{H}, \mathrm{t}$, $J=7.0 \mathrm{~Hz}), 7.05(1 \mathrm{H}, \mathrm{t}, J=7.0 \mathrm{~Hz}), 7.45(1 \mathrm{H}, \mathrm{d}$, $J=8.5 \mathrm{~Hz}), 7.66(1 \mathrm{H}, \mathrm{d}, J=8.0 \mathrm{~Hz}), 7.79(1 \mathrm{H}, \mathrm{d}$, $J=1.5 \mathrm{~Hz}), 8.08(1 \mathrm{H}, \mathrm{s}), 8.26(1 \mathrm{H}, \mathrm{d}, J=6.5 \mathrm{~Hz})$, 
$11.72\left(1 \mathrm{H}, \mathrm{s}, \mathrm{NH}_{\text {ind }}\right) .{ }^{13} \mathrm{C}$ NMR $\left(100 \mathrm{MHz}\right.$, DMSO- $\left.d_{6}\right)$ : $23.9\left(\mathrm{~N}-\mathrm{CH}_{3}\right), 60.8\left(\mathrm{C}_{6^{\prime}}\right), 69.5,72.5,76.9,80.7,86.6\left(\mathrm{C}_{1^{\prime}}\right.$, $\left.\mathrm{C}_{2^{\prime}}, \mathrm{C}_{3^{\prime}}, \mathrm{C}_{4^{\prime}}, \mathrm{C}_{5^{\prime}}\right), 110.5,111.8,119.4,120.9,121.6,128.3$, $128.6,133.5,148.7$ (C tert arom), 105.5, 106.2, 123.8, 124.8, 126.7, 128.2, 136.0, 150.2 (C quat arom), 171.9, $172.0(\mathrm{C}=\mathrm{O})$.

4.1.3. 6-Methyl-1-(2,3,4,6-tetra- $O$-acetyl- $\beta$-D-glucopyranos-1-yl)-1 $H$-pyrido $\left[3^{\prime}, 2^{\prime}: 4,5\right]$ pyrrolo[2,3-a]pyrrolo[3,4c|carbazole-5,7(12H)-dione (13). A mixture of 11 (70 mg, $0.104 \mathrm{mmol}$ ) and iodine (290 $\mathrm{mg}, 1.14 \mathrm{mmol})$ in benzene $(150 \mathrm{~mL})$ was irradiated for $4 \mathrm{~h}$ with a medium-pressure mercury lamp $(400 \mathrm{~W})$. The solvent was removed, and the residue was dissolved in EtOAc and washed with saturated aqueous sodium thiosulfate $(100 \mathrm{~mL})$, then with brine $(100 \mathrm{~mL})$. The organic phase was dried over $\mathrm{MgSO}_{4}$. After removal of the solvent, the residue was purified by flash chromatography (eluent: EtOAc/cyclohexane $5: 5)$ to give $\mathbf{1 3}(49 \mathrm{mg}, 0.073 \mathrm{mmol}, 70 \%$ yield) as an orange solid.

Mp: $128-130{ }^{\circ} \mathrm{C}$. IR (KBr) $v_{\mathrm{C}=\mathrm{O}} 1700,1750 \mathrm{~cm}^{-1}, v_{\mathrm{NH}}$ $3200-3600 \mathrm{~cm}^{-1}$. HRMS (ESI+) $[\mathrm{M}+\mathrm{H}]^{+}$calcd for $\mathrm{C}_{34} \mathrm{H}_{31} \mathrm{~N}_{4} \mathrm{O}_{11}$ 671.1989, found 671.1982. ${ }^{1} \mathrm{H}$ NMR $\left(400 \mathrm{MHz}, \mathrm{CDCl}_{3}\right): 1.33\left(3 \mathrm{H}, \mathrm{s}, \mathrm{CH}_{3} \mathrm{CO}\right), 1.97(3 \mathrm{H}, \mathrm{s}$, $\left.\mathrm{CH}_{3} \mathrm{CO}\right), 2.10\left(3 \mathrm{H}, \mathrm{s}, \mathrm{CH}_{3} \mathrm{CO}\right), 2.11\left(3 \mathrm{H}, \mathrm{s}, \mathrm{CH}_{3} \mathrm{CO}\right)$, $3.15\left(3 \mathrm{H}, \mathrm{s}, \mathrm{N}-\mathrm{CH}_{3}\right), 4.344 .43(3 \mathrm{H}, \mathrm{m}), 5.29(1 \mathrm{H}, \mathrm{t}$, $J=9.5 \mathrm{~Hz}), 5.38(1 \mathrm{H}, \mathrm{t}, J=9.5 \mathrm{~Hz}), 5.65(1 \mathrm{H}, \mathrm{t}$, $J=9.5 \mathrm{~Hz}), 6.72(1 \mathrm{H}, \mathrm{t}, J=7.0 \mathrm{~Hz}), 6.79(1 \mathrm{H}, \mathrm{d}$, $\left.J=9.0 \mathrm{~Hz}, \mathrm{H}_{1^{\prime}}\right), 7.27\left(1 \mathrm{H}, \mathrm{dt}, J_{1}=8.0 \mathrm{~Hz}, J_{2}=1.5 \mathrm{~Hz}\right)$, $7.42(2 \mathrm{H}, \mathrm{t}, J=6.5 \mathrm{~Hz}), 7.79(1 \mathrm{H}, \mathrm{d}, J=7.0 \mathrm{~Hz}), 8.89$ $(1 \mathrm{H}, \mathrm{d}, J=8.0 \mathrm{~Hz}), 8.93(1 \mathrm{H}, \mathrm{d}, J=7.0 \mathrm{~Hz}), 9.66(1 \mathrm{H}$, $\left.\mathrm{s}, \mathrm{NH}_{\text {ind }}\right) .{ }^{13} \mathrm{C}$ NMR $\left(100 \mathrm{MHz}, \mathrm{CDCl}_{3}\right): 19.8,20.5$, 20.7, $20.9\left(\mathrm{CH}_{3} \mathrm{CO}\right), 23.6\left(\mathrm{~N}-\mathrm{CH}_{3}\right), 62.2\left(\mathrm{C}_{6^{\prime}}\right), 67.8$, 72.4, 73.6, 75.5, 83.7 $\left(\mathrm{C}_{1^{\prime}}, \mathrm{C}_{2^{\prime}}, \mathrm{C}_{3^{\prime}}, \mathrm{C}_{4^{\prime}}, \mathrm{C}_{5^{\prime}}\right), 109.9$, $111.0,120.6,125.3,127.0,128.5,136.3$ (C tert arom), $115.0,117.7,119.3,120.1,122.3,124.9,132.6,140.1$, 141.1, 152.9 (C quat arom), 169.0, 169.6, 169.9, 170.1, $170.3,170.8(\mathrm{C}=\mathrm{O})$.

4.1.4. 1-( $\beta$-D-Glucopyranos-1-yl)-6-methyl-1 $H$-pyrido[ $\left[3^{\prime}, 2^{\prime}: 4,5\right]$ pyrrolo $[2,3-a \mid$ pyrrolo $[3,4-c \mid$ carbazole-5,7(12H)dione (14). To a solution of $13(45 \mathrm{mg}, 0.067 \mathrm{mmol})$ in methanol $(20 \mathrm{~mL})$ was added $28 \%$ aqueous $\mathrm{NH}_{4} \mathrm{OH}$ $(31 \mathrm{~mL})$. The mixture was stirred at $65^{\circ} \mathrm{C}$ for $22 \mathrm{~h}$. After removal of the solvent, water and EtOAc were added and the mixture was filtered off. The solid residue was washed with EtOAc to give 14 (23 mg, $0.046 \mathrm{mmol}$, 69 $\%$ yield) as a red solid.

Mp: $290-295{ }^{\circ} \mathrm{C}$ (decomposition). IR (KBr) $v_{\mathrm{C}=\mathrm{O}} 1690$, $1740 \mathrm{~cm}^{-1}, v_{\mathrm{NH}, \mathrm{OH}} 3200-3600 \mathrm{~cm}^{-1}$. HRMS (FAB+) $[\mathrm{M}+\mathrm{H}]^{+}$calcd for $\mathrm{C}_{26} \mathrm{H}_{23} \mathrm{~N}_{4} \mathrm{O}_{7}$ 503.1566, found: 503.1569. ${ }^{1} \mathrm{H}$ NMR $\left(400 \mathrm{MHz}\right.$, DMSO- $\left.d_{6}\right): 3.18(3 \mathrm{H}$, $\left.\mathrm{s}, \mathrm{CH}_{3}\right), 3.48-3.60(4 \mathrm{H}, \mathrm{m}), 3.81(1 \mathrm{H}, \mathrm{d}, J=4.0 \mathrm{~Hz})$, $3.96(1 \mathrm{H}, \mathrm{m}), 4.71(1 \mathrm{H}$, br s, OH $), 5.33(1 \mathrm{H}$, br s, $\mathrm{OH}), 5.48(1 \mathrm{H}$, br s, OH $), 5.57(1 \mathrm{H}, \mathrm{d}, J=4.5 \mathrm{~Hz}$, $\mathrm{OH}), 6.78\left(1 \mathrm{H}, \quad \mathrm{d}, J=9.0 \mathrm{~Hz}, \mathrm{H}_{1^{\prime}}\right), 7.33(1 \mathrm{H}, \mathrm{t}$, $J=7.5 \mathrm{~Hz}), 7.39(1 \mathrm{H}, \mathrm{t}, J=7.0 \mathrm{~Hz}), 7.52(1 \mathrm{H}, \mathrm{t}$, $J=7.5 \mathrm{~Hz}), 7.68(1 \mathrm{H}, \mathrm{d}, J=8.0 \mathrm{~Hz}), 8.67(1 \mathrm{H}, \mathrm{d}$, $J=6.5 \mathrm{~Hz}), 8.97(1 \mathrm{H}, \mathrm{d}, J=7.5 \mathrm{~Hz}), 9.40(1 \mathrm{H}, \mathrm{d}$, $J=7.0 \mathrm{~Hz}), \quad 12.55 \quad\left(1 \mathrm{H}, \quad \mathrm{s}, \quad \mathrm{NH}_{\text {ind }}\right) .{ }^{13} \mathrm{C} \quad \mathrm{NMR}$ $\left(100 \mathrm{MHz}, \mathrm{DMSO}-d_{6}\right): 23.5\left(\mathrm{~N}-\mathrm{CH}_{3}\right), 60.9\left(\mathrm{C}_{6^{\prime}}\right), 69.5$,
72.6, 77.1, 81.1, 86.5 $\left(\mathrm{C}_{1^{\prime}}, \mathrm{C}_{2^{\prime}}, \mathrm{C}_{3^{\prime}}, \mathrm{C}_{4^{\prime}}, \mathrm{C}_{5^{\prime}}\right), 109.8$, $111.9,119.8,124.0,126.5,128.3,135.6$ (C tert arom), $114.9,116.1,118.1,119.6,121.6,124.1,132.6,140.8$, $142.7,154.1$ (C quat arom), $170.3(2 \mathrm{C}=\mathrm{O})$.

4.1.5. 3-[7-( 3 -D-Glucopyranos-1-yl)-7H-pyrrolo[2,3b|pyridin-3-yl|-4-(1 $H$-indol-3-yl)-furane-2,5-dione (15). To a suspension of $12(50 \mathrm{mg}, 0.074 \mathrm{mmol})$ in water $(40 \mathrm{~mL})$ were added $\mathrm{NaOH}(44.5 \mathrm{mg}, 1.1 \mathrm{mmol})$ and THF $(5 \mathrm{~mL})$. The mixture was stirred at room temperature for $2 \mathrm{~h}$, then was acidified to $\mathrm{pH} 1$ with $2 \mathrm{~N} \mathrm{HCl}$. The mixture was stirred overnight at room temperature. After evaporation, the residue was purified by flash chromatography (eluent: THF/methanol 95:5) to yield $15(21.8 \mathrm{mg}, 0.044 \mathrm{mmol}, 60 \%$ yield $)$ as a red solid.

Mp: $\quad 168-170^{\circ} \mathrm{C}$. IR $(\mathrm{KBr}) \quad v_{\mathrm{C}=\mathrm{O}} \quad 1750,1820 \mathrm{~cm}^{-1}$, $v_{\mathrm{NH}, \mathrm{OH}} 3000-3600 \mathrm{~cm}^{-1}$. HRMS (ESI+) $[\mathrm{M}+\mathrm{H}]^{+}$calcd for $\mathrm{C}_{25} \mathrm{H}_{22} \mathrm{~N}_{3} \mathrm{O}_{8}$ 492.1407, found 492.1403. ${ }^{1} \mathrm{H}$ NMR $\left(400 \mathrm{MHz}\right.$, DMSO- $\left.d_{6}\right): 3.45-3.55(3 \mathrm{H}, \mathrm{m}), 3.72-3.85$ $(2 \mathrm{H}, \mathrm{m}), 4.10(1 \mathrm{H}, \mathrm{m}), 4.64(1 \mathrm{H}, \mathrm{t}, J=5.5 \mathrm{~Hz}, \mathrm{OH})$, $5.22(1 \mathrm{H}, \mathrm{d}, J=5.5 \mathrm{~Hz}, \mathrm{OH}), 5.30-5.40(2 \mathrm{H}, \mathrm{m}, 2 \mathrm{OH})$, $6.51\left(1 \mathrm{H}, \mathrm{d}, J=9.5 \mathrm{~Hz}, \mathrm{H}_{1^{\prime}}\right), 6.75(1 \mathrm{H}, \mathrm{d}, J=7.5 \mathrm{~Hz})$, $6.80(1 \mathrm{H}, \mathrm{d}, J=8.0 \mathrm{~Hz}), 6.96(1 \mathrm{H}, \mathrm{t}, J=7.0 \mathrm{~Hz}), 7.07$ $(1 \mathrm{H}, \mathrm{t}, J=8.0 \mathrm{~Hz}), 7.46(1 \mathrm{H}, \mathrm{d}, J=8.0 \mathrm{~Hz}), 7.73(1 \mathrm{H}$, d, $J=7.5 \mathrm{~Hz}), 7.88(1 \mathrm{H}, \mathrm{d}, J=3.0 \mathrm{~Hz}), 8.10(1 \mathrm{H}, \mathrm{s})$, $8.33(1 \mathrm{H}, \mathrm{d}, J=6.5 \mathrm{~Hz}), 12.10\left(1 \mathrm{H}, \mathrm{s}, \mathrm{NH}_{\text {ind }}\right) .{ }^{13} \mathrm{C}$ NMR $\left(100 \mathrm{MHz}\right.$, DMSO- $\left.d_{6}\right): 60.7\left(\mathrm{C}_{6^{\prime}}\right), 69.5,72.5$, 76.9, 80.7, $86.7\left(\mathrm{C}_{1^{\prime}}, \mathrm{C}_{2^{\prime}}, \mathrm{C}_{3^{\prime}}, \mathrm{C}_{4^{\prime}}, \mathrm{C}_{5^{\prime}}\right), 111.4,112.2$, $119.8,121.1,122.0,129.0,129.7,134.1,149.8$ (C tert arom), 104.7, 105.4, 124.3, 124.4, 126.3, 129.1, 136.1, 150.7 (C quat arom), 166.6, $166.7(2 \mathrm{C}, \mathrm{C}=\mathrm{O})$.

4.1.6. 1-Benzyloxymethyl-3-[1-phenylsulfonyl-indol-3-yl]4-[7-(2-O-tosyl-3,4,6-tri- $O$-benzyl- $\beta$-D-glucopyranos-1yl)-7H-pyrrolo[2,3-b]pyridin-3-yl]-pyrrole-2,5-dione (16). To a solution of aglycone $\mathbf{C}(200 \mathrm{mg}, 0.341 \mathrm{mmol})$ in THF $(18 \mathrm{~mL})$ were added D (459 mg, $0.76 \mathrm{mmol})$ and triphenylphosphine $(199 \mathrm{mg}, 0.76 \mathrm{mmol})$. The mixture was cooled to $-78^{\circ} \mathrm{C}$, then diisopropyl azodicarboxylate (DIAD) $(147 \mu \mathrm{L}, 0.76 \mathrm{mmol})$ was added dropwise. The mixture was allowed to reach room temperature, then was stirred at room temperature for $18 \mathrm{~h}$. Water $(50 \mathrm{~mL})$ was added. After extraction with EtOAc, the organic phase was dried over $\mathrm{MgSO}_{4}$, and the solvent was removed. The residue was purified by flash chromatography (eluent: $\mathrm{CH}_{2} \mathrm{Cl}_{2} /$ EtOAc 9:1) to give $\mathbf{1 6}$ (69 mg, $0.058 \mathrm{mmol}, 17 \%$ yield) as a red solid.

Mp: $63-65^{\circ} \mathrm{C}$. IR (KBr) $v_{\mathrm{C}=\mathrm{O}} 1706 \mathrm{~cm}^{-1} \cdot{ }^{1} \mathrm{H}$ NMR $\left(400 \mathrm{MHz}, \mathrm{CDCl}_{3}\right): 2.11\left(3 \mathrm{H}, \mathrm{s}, \mathrm{CH}_{3}\right), 3.51-3.60(1 \mathrm{H}$, $\mathrm{m}), 3.63\left(1 \mathrm{H}, \mathrm{dd}, J_{1}=11.0 \mathrm{~Hz}, J_{2}=3.5 \mathrm{~Hz}\right), 3.70(1 \mathrm{H}$, d, $J=10.0 \mathrm{~Hz}), 3.82(1 \mathrm{H}, \mathrm{t}, J=9.0 \mathrm{~Hz}), 3.90(1 \mathrm{H}, \mathrm{t}$, $J=9.0 \mathrm{~Hz}), 4.34(1 \mathrm{H}, \mathrm{d}, J=12.0 \mathrm{~Hz}), 4.42(1 \mathrm{H}, \mathrm{d}$, $J=12.0 \mathrm{~Hz}), 4.43(1 \mathrm{H}, \mathrm{d}, J=10.5 \mathrm{~Hz}), 4.56(1 \mathrm{H}, \mathrm{d}$, $J=10.5 \mathrm{~Hz}), 4.62(2 \mathrm{H}, \mathrm{s}), 4.68(1 \mathrm{H}, \mathrm{d}, J=11.0 \mathrm{~Hz})$, $4.69(1 \mathrm{H}, \mathrm{d}, J=10.5 \mathrm{~Hz}), 4.84\left(1 \mathrm{H}, \mathrm{t}, J=9.0 \mathrm{~Hz}, \mathrm{H}_{2^{\prime}}\right)$, $5.14(2 \mathrm{H}$, AB system, $J=10.5 \mathrm{~Hz}, \Delta v=7.5 \mathrm{~Hz}), 6.37$ $(1 \mathrm{H}, \mathrm{t}, J=7.0 \mathrm{~Hz}), 6.64-6.73(2 \mathrm{H}, \mathrm{m}), 6.76(1 \mathrm{H}, \mathrm{d}$, $\left.J=9.0 \mathrm{~Hz}, \mathrm{H}_{1^{\prime}}\right), 6.82(2 \mathrm{H}, \mathrm{d}, J=8.5 \mathrm{~Hz}), 6.92(2 \mathrm{H}, \mathrm{d}$, $J=8.0 \mathrm{~Hz}), \quad 6.96-7.02 \quad(3 \mathrm{H}, \mathrm{m}), \quad 7.05 \quad(1 \mathrm{H}, \quad \mathrm{dt}$, $\left.J_{1}=8.5 \mathrm{~Hz}, \quad J_{2}=1.5 \mathrm{~Hz}\right), \quad 7.09-7.23 \quad\left(14 \mathrm{H}_{\mathrm{arom}}\right), \quad 7.24$ $(1 \mathrm{H}, \mathrm{d}, J=7.5 \mathrm{~Hz}), 7.28(2 \mathrm{H}, \mathrm{d}, J=7.5 \mathrm{~Hz}), 7.38(2 \mathrm{H}$, 
$\mathrm{t}, J=7.5 \mathrm{~Hz}), 7.48(1 \mathrm{H}, \mathrm{t}, J=7.0 \mathrm{~Hz}), 7.64(1 \mathrm{H}, \mathrm{m})$, $7.68(1 \mathrm{H}, \mathrm{d}, J=6.5 \mathrm{~Hz}), 7.86(3 \mathrm{H}, \mathrm{d}, J=7.5 \mathrm{~Hz}), 7.95$ $(1 \mathrm{H}, \mathrm{s}), 8.27(1 \mathrm{H}, \mathrm{s}) .{ }^{13} \mathrm{C}$ NMR $\left(100 \mathrm{MHz}, \mathrm{CDCl}_{3}\right)$ : $16.3\left(\mathrm{CH}_{3}\right), 62.2,62.6,64.8,66.5,70.1,70.6\left(\mathrm{C}_{6^{\prime}}+\right.$ $\left.5 \mathrm{CH}_{2}\right), 71.8,73.1,74.6,77.4,78.6\left(\mathrm{C}_{1^{\prime}}, \mathrm{C}_{2^{\prime}}, \mathrm{C}_{3^{\prime}}, \mathrm{C}_{4^{\prime}}\right.$, $\left.\mathrm{C}_{5^{\prime}}\right), 106.3,108.2,117.0,118.5,119.8,121.3-127.5$, $128.9,146.5$ (C tert arom), 101.5, 107.6, 114.8, 127.3, $127.5,128.9,129.3,132.1,132.2,132.3,132.5,132.6$, 139.6, 145.7 (C quat arom), 165.6, $165.9(\mathrm{C}=\mathrm{O})$.

4.1.7. 1-Benzyloxymethyl-3-(1 $\mathrm{H}$-indol-3-yl)-4-[7-(2-Otosyl-3,4,6-tri- $O$-benzyl- $\beta$-D-glucopyranos-1-yl)-7 $H$-pyrrolo[2,3-b]pyridin-3-yl|-pyrrole-2,5-dione (18). To a solution of $16(69 \mathrm{mg}, 0.059 \mathrm{mmol})$ in THF $(3 \mathrm{~mL})$ was added $1.1 \mathrm{M} n$ - $\mathrm{Bu}_{4} \mathrm{NF}$ in THF $(177 \mathrm{~mL})$. The mixture was stirred at room temperature for $2.5 \mathrm{~h}$. Water $(45 \mathrm{~mL})$ was added. After extraction with EtOAc, the organic phase was dried over $\mathrm{MgSO}_{4}$. The solvent was removed and the residue was purified by flash chromatography (eluent: $\mathrm{CH}_{2} \mathrm{Cl}_{2} \quad 100 \%$ to $\mathrm{CH}_{2} \mathrm{Cl}_{2} /$ EtOAc 8:2) to give 18 (36 mg, $0.035 \mathrm{mmol}, 59 \%$ yield) as a red solid.

Mp: $93-95^{\circ} \mathrm{C}$. IR (KBr) $v_{\mathrm{C}=\mathrm{O}} 1706,1755 \mathrm{~cm}^{-1}, v_{\mathrm{NH}}$ $3500 \mathrm{~cm}^{-1}$. Mass (ESI+) $[\mathrm{M}+\mathrm{H}]^{+} 1035 .{ }^{1} \mathrm{H}$ NMR $\left(400 \mathrm{MHz}, \mathrm{CDCl}_{3}\right): 2.14\left(3 \mathrm{H}, \mathrm{s}, \mathrm{CH}_{3}\right), 3.61(1 \mathrm{H}, \mathrm{d}$, $J=10.5 \mathrm{~Hz}), 3.67\left(1 \mathrm{H}, \mathrm{dd}, J_{1}=11.0 \mathrm{~Hz}, J_{2}=3.0 \mathrm{~Hz}\right)$, $3.75(1 \mathrm{H}, \mathrm{m}), \quad 3.82-3.92(2 \mathrm{H}, \mathrm{m}), 4.38(1 \mathrm{H}, \mathrm{d}$, $J=12.0 \mathrm{~Hz}), 4.45(1 \mathrm{H}, \mathrm{d}, J=12.0 \mathrm{~Hz}), 4.47(1 \mathrm{H}, \mathrm{d}$, $J=11.0 \mathrm{~Hz}), 4.57(1 \mathrm{H}, \mathrm{d}, J=10.5 \mathrm{~Hz}), 4.66(2 \mathrm{H}, \mathrm{s})$, $4.71(1 \mathrm{H}, \mathrm{d}, J=10.5 \mathrm{~Hz}), 4.73(1 \mathrm{H}, \mathrm{d}, J=9.5 \mathrm{~Hz})$, $4.91\left(1 \mathrm{H}, \mathrm{t}, J=8.5 \mathrm{~Hz}, \mathrm{H}_{2^{\prime}}\right), 5.16(2 \mathrm{H}, \mathrm{AB}$ system, $J=11.0 \mathrm{~Hz}, \Delta v=8.0 \mathrm{~Hz}), 6.55(1 \mathrm{H}, \mathrm{t}, \quad J=7.0 \mathrm{~Hz})$, $6.66(1 \mathrm{H}, \mathrm{t}, J=7.5 \mathrm{~Hz}), 6.80-6.90\left(3 \mathrm{H}+\mathrm{H}_{1^{\prime}}, \mathrm{m}\right), 6.90$ $7.00(3 \mathrm{H}, \mathrm{m}), 7.00-7.08(3 \mathrm{H}, \mathrm{m}), 7.10-7.30\left(17 \mathrm{H}_{\text {arom }}\right)$, $7.33(2 \mathrm{H}, \mathrm{d}, J=7.5 \mathrm{~Hz}), 7.37(1 \mathrm{H}, \mathrm{d}, J=7.5 \mathrm{~Hz}), 7.65$ $(1 \mathrm{H}, \mathrm{d}, J=2.5 \mathrm{~Hz}), 7.70(1 \mathrm{H}, \mathrm{d}, J=6.5 \mathrm{~Hz}), 8.32(1 \mathrm{H}$, s), $8.90(1 \mathrm{H}, \mathrm{s}) .{ }^{13} \mathrm{C} \mathrm{NMR}\left(100 \mathrm{MHz}, \mathrm{CDCl}_{3}\right): 21.5$ $\left(\mathrm{CH}_{3}\right), 67.2,67.9,71.6,73.4,75.4,75.9\left(\mathrm{C}_{6^{\prime}}+5 \mathrm{CH}_{2}\right)$, $77.2,78.4,80.0,82.8,83.8\left(\mathrm{C}_{1^{\prime}}, \mathrm{C}_{2^{\prime}}, \mathrm{C}_{3^{\prime}}, \mathrm{C}_{4^{\prime}}, \mathrm{C}_{5^{\prime}}\right)$, $111.0,111.4,120.7,122.1,122.7,126.1,126.8,126.9-$ $128.6,129.5$ (2C), 134.3, 150.5 (C tert arom), 107.0, $107.2,124.5,125.3,128.9,132.6,135.9,137.5,137.6$, $137.7,137.8,144.8,150.5$ (C quat arom), 171.9, 172.0 $(\mathrm{C}=\mathrm{O})$.

4.1.8. 6-Benzyloxymethyl-1-(2- $O$-tosyl-3,4,6-tri- $O$-benzyl-p-D-glucopyranos-1-yl)- $1 H$-pyrido $\left[3^{\prime}, 2^{\prime}: 4,5\right]$ pyrrolo $[2,3-$ a]pyrrolo[3,4-c]carbazole-5,7(12H)-dione (20). A mixture of 18 (180 mg, $0.174 \mathrm{mmol})$ and iodine $(66 \mathrm{mg}$, $0.259 \mathrm{mmol})$ in benzene $(300 \mathrm{~mL})$ was irradiated according to the procedure described for the synthesis of compound 13. After identical work-up, the residue was purified by flash chromatography (eluent: cyclohexane/ EtOAc 7:3) to give $20(135 \mathrm{mg}, 0.130 \mathrm{mmol}, 75 \%$ yield $)$ as a yellow solid.

Mp: $53-55^{\circ} \mathrm{C}$. IR (KBr) $v_{\mathrm{C}=\mathrm{O}} 1707,1753 \mathrm{~cm}^{-1}, v_{\mathrm{NH}}$ $2926 \mathrm{~cm}^{-1}$. Mass (APCI+) $[\mathrm{M}-\mathrm{OTs}]^{+} 861 .{ }^{1} \mathrm{H}$ NMR $\left(400 \mathrm{MHz}, \mathrm{CDCl}_{3}\right): 1.54\left(3 \mathrm{H}, \mathrm{s}, \mathrm{CH}_{3}\right), 3.70-3.81(2 \mathrm{H}$, m), $3.88-4.10(3 \mathrm{H}, \mathrm{m}), 4.48(1 \mathrm{H}, \mathrm{d}, J=12.5 \mathrm{~Hz}), 4.53$ $(1 \mathrm{H}, \mathrm{d}, J=11.0 \mathrm{~Hz}), 4.54(1 \mathrm{H}, \mathrm{d}, J=11.5 \mathrm{~Hz}), 4.57$ $(1 \mathrm{H}, \quad \mathrm{d}, J=9.5 \mathrm{~Hz}), 4.71(2 \mathrm{H}, \mathrm{s}), 4.79(1 \mathrm{H}, \mathrm{d}$, $J=11.0 \mathrm{~Hz}), 4.82(1 \mathrm{H}, \mathrm{d}, J=10.0 \mathrm{~Hz}), 4.99(1 \mathrm{H}$, br s$)$,
$5.25(2 \mathrm{H}$, AB system, $J=11.0 \mathrm{~Hz}, \Delta v=10.0 \mathrm{~Hz}), 6.07$ $(2 \mathrm{H}, \mathrm{d}, J=8.5 \mathrm{~Hz}), 6.70(2 \mathrm{H}, \mathrm{d}, J=8.0 \mathrm{~Hz}), 6.74(1 \mathrm{H}$, $\mathrm{t}, J=8.0 \mathrm{~Hz}), 6.80(1 \mathrm{H}, \mathrm{m}), 7.05-7.50\left(23 \mathrm{H}_{\text {arom }}\right), 7.77$ $(1 \mathrm{H}, \mathrm{d}, J=6.5 \mathrm{~Hz}), 8.948 .99(2 \mathrm{H}, \mathrm{m}), 10.27(1 \mathrm{H}, \mathrm{s}$, NH). ${ }^{13} \mathrm{C}$ NMR $\left(100 \mathrm{MHz}, \mathrm{CDCl}_{3}\right): 21.9\left(\mathrm{CH}_{3}\right), 66.9$, 68.0, 71.6, 73.5, 75.1, $75.9\left(\mathrm{C}_{6}+5 \mathrm{CH}_{2}\right), 70.1,77.1$, 78.6, 80.7, 81.9 $\left(\mathrm{C}_{1^{\prime}}, \mathrm{C}_{2^{\prime}}, \mathrm{C}_{3^{\prime}}, \mathrm{C}_{4^{\prime}}, \mathrm{C}_{5^{\prime}}\right), 112.1,121.2$, $125.1,126.0,127.8-129.0,130.0,130.9$ (C tert arom), $118.3,118.8,121.3,130.6,132.4,137.6$ (several C), 137.7, 141.0, 144.4, 156.7 (C quat arom), 168.9 (2C, $\mathrm{C}=\mathrm{O})$.

4.1.9. 1-(2-O-Tosyl- $\beta$-D-glucopyranos-1-yl)- $1 H$-pyrido[3', $\left.2^{\prime}: 4,5\right]$ pyrrolo $[2,3-a]$ pyrrolo $[3,4-c]$ carbazole-5,7$(6 \boldsymbol{H}, 12 \mathrm{H})$-dione (22). To a suspension of 20 (120 mg, $0.115 \mathrm{mmol})$ in $\mathrm{CH}_{2} \mathrm{Cl}_{2}(12 \mathrm{~mL})$ at $-78^{\circ} \mathrm{C}$ was added $1 \mathrm{M} \mathrm{BBr} 3$ in $\mathrm{CH}_{2} \mathrm{Cl}_{2}(1.87 \mathrm{~mL})$. The mixture was stirred at $-78^{\circ} \mathrm{C}$ for $30 \mathrm{~min}$, then water was added. After extraction with EtOAc, the organic phase was dried over $\mathrm{MgSO}_{4}$, and the solvent was removed. To a solution of the residue $(41 \mathrm{mg})$ in THF $(6 \mathrm{~mL})$ was added $28 \%$ aqueous $\mathrm{NH}_{4} \mathrm{OH}(12 \mathrm{~mL})$. The mixture was stirred at room temperature overnight. After evaporation, the residue was purified by flash chromatography (eluent: EtOAc $100 \%$ to EtOAc/methanol $95: 5$ ) to give 22 (30 $\mathrm{mg}, 0.047 \mathrm{mmol}, 41 \%$ yield) as an orange solid.

$\mathrm{Mp}: \quad 200{ }^{\circ} \mathrm{C}$ (degradation). IR ( $\left.\mathrm{KBr}\right) \quad v_{\mathrm{C}=\mathrm{O}} \quad 1705$, $1741 \mathrm{~cm}^{-1}, \quad v_{\mathrm{NH}} \quad 3018-3642 \mathrm{~cm}^{-1}$. HRMS (FAB+) $[\mathrm{M}+\mathrm{H}]^{+}$calcd for $\mathrm{C}_{32} \mathrm{H}_{26} \mathrm{~N}_{4} \mathrm{O}_{9} \mathrm{~S}$ 669.0846, found 669.0856. ${ }^{1} \mathrm{H}$ NMR (400 MHz, DMSO- $\left.d_{6}\right): 1.83(3 \mathrm{H}$, $\left.\mathrm{s}, \mathrm{CH}_{3}\right), 3.50-3.61(2 \mathrm{H}, \mathrm{m}), 3.64(1 \mathrm{H}, \mathrm{m}), 3.74(1 \mathrm{H}, \mathrm{m}$, $\left.\mathrm{H}_{3^{\prime}}\right), 3.81\left(1 \mathrm{H}, \mathrm{dd}, J_{1}=11.5 \mathrm{~Hz}, J_{2}=4.0 \mathrm{~Hz}, \mathrm{H}_{6^{\prime}}\right), 4.74$ $\left(1 \mathrm{H}, \mathrm{t}, J=5.5 \mathrm{~Hz}, \mathrm{OH}_{6^{\prime}}\right), 5.15\left(1 \mathrm{H}, \mathrm{t}, J=9.0 \mathrm{~Hz}, \mathrm{H}_{2^{\prime}}\right)$, $5.63\left(1 \mathrm{H}\right.$, br s, OH), $5.92\left(1 \mathrm{H}, \mathrm{d}, J=4.0 \mathrm{~Hz}, \mathrm{OH}_{3^{\prime}}\right)$, $5.60(2 \mathrm{H}, \mathrm{d}, J=8.0 \mathrm{~Hz}), 6.92(2 \mathrm{H}, \mathrm{d}, J=8.5 \mathrm{~Hz}), 6.93$ $\left(1 \mathrm{H}, \mathrm{d}, J=9.0 \mathrm{~Hz}, \mathrm{H}_{1^{\prime}}\right), 7.28(1 \mathrm{H}, \mathrm{t}, J=7.0 \mathrm{~Hz}), 7.32$ $(1 \mathrm{H}, \mathrm{t}, J=7.0 \mathrm{~Hz}), 7.53(1 \mathrm{H}, \mathrm{t}, J=7.5 \mathrm{~Hz}), 7.68(1 \mathrm{H}$, d, $J=8.0 \mathrm{~Hz}), 8.70(1 \mathrm{H}, \mathrm{d}, J=6.5 \mathrm{~Hz}), 8.98(1 \mathrm{H}, \mathrm{d}$, $J=8.0 \mathrm{~Hz}), 8.19(1 \mathrm{H}, \mathrm{d}, J=7.5 \mathrm{~Hz}), 10.94(1 \mathrm{H}, \mathrm{br} \mathrm{s}$, $\mathrm{NH}), 12.45(1 \mathrm{H}, \mathrm{s}, \mathrm{NH}) .{ }^{13} \mathrm{C} \mathrm{NMR}\left(100 \mathrm{MHz}, \mathrm{CDCl}_{3}\right)$ : $20.3\left(\mathrm{CH}_{3}\right), 60.7\left(\mathrm{C}_{6^{\prime}}\right), 69.4,74.6,81.0,81.9,83.1\left(\mathrm{C}_{1^{\prime}}\right.$, $\left.\mathrm{C}_{2^{\prime}}, \quad \mathrm{C}_{3^{\prime}}, \quad \mathrm{C}_{4^{\prime}}, \mathrm{C}_{5^{\prime}}\right), 109.9,111.8,119.7,124.1,125.6$ (2C), 126.5, 128.6 (2C), 131.8, 135.7 (C tert arom), $114.9,116.1,119.1,120.4,121.6,124.2,133.0,133.5$, $140.8,142.7,143.5,153.2$ (C quat arom), 171.5, 171.7 $(\mathrm{C}=\mathrm{O})$.

4.1.10. 1-Benzyloxymethyl-4-(1-phenylsulfonyl-indol-3yl)-3-[7-(2,3,4,6-tetra- $O$-benzyl- $\beta$-D-glucopyranos-1-yl)7H-pyrrolo[2,3-b]pyridin-3-yl]-pyrrole-2,5-dione (17). To a solution of aglycone $\mathbf{C}(500 \mathrm{mg}, 0.852 \mathrm{mmol})$ in THF $(5 \mathrm{~mL})$ were added 2,3,4,6-tetra- $O$-benzyl- $\alpha$-Dglucopyranose E $(1.364 \mathrm{~g}, 2.25 \mathrm{mmol})$ and triphenylphosphine $(786 \mathrm{mg}, 2.25 \mathrm{mmol})$. The mixture was cooled to $-78{ }^{\circ} \mathrm{C}$, then DIAD $(500 \mu \mathrm{L}, 2.25 \mathrm{mmol})$ was added dropwise. After identical work-up as described for the synthesis of compound $\mathbf{1 6}$, the residue was purified by flash chromatography (eluent: $\mathrm{CH}_{2} \mathrm{Cl}_{2} /$ EtOAc 95:5) to give $\mathbf{G}$ (in mixture with starting products) and 17 (234 mg, $0.215 \mathrm{mmol}, 25 \%$ yield) as red solids. Compound $\mathbf{G}$ cannot be purified by chromatography. 
Mp: $83-85^{\circ} \mathrm{C}$. IR $(\mathrm{KBr}) v_{\mathrm{C}=\mathrm{O}} 1707,1762 \mathrm{~cm}^{-1}$. Mass $(\mathrm{ESI}+)[\mathrm{M}+\mathrm{Na}]^{+}$1133, $[\mathrm{M}+\mathrm{K}]^{+}$1149. ${ }^{1} \mathrm{H} \quad \mathrm{NMR}$ $\left(400 \mathrm{MHz}, \mathrm{CDCl}_{3}\right): 3.57-3.61(2 \mathrm{H}, \mathrm{m}), 3.70(1 \mathrm{H}, \mathrm{dd}$, $\left.J_{1}=11.0 \mathrm{~Hz}, \quad J_{2}=3.0 \mathrm{~Hz}\right), 3.73-3.81(3 \mathrm{H}, \mathrm{m}), 3.94$ $(1 \mathrm{H}, \mathrm{t}, J=8.5 \mathrm{~Hz}), 4.19(1 \mathrm{H}, \mathrm{d}, J=11.0 \mathrm{~Hz}), 4.38$ $(1 \mathrm{H}, \mathrm{d}, J=12.0 \mathrm{~Hz}), 4.45(1 \mathrm{H}, \mathrm{d}, J=12.0 \mathrm{~Hz}), 4.53$ $(1 \mathrm{H}, \quad \mathrm{d}, J=11.0 \mathrm{~Hz}), 4.65(2 \mathrm{H}, \mathrm{s}), 4.78(1 \mathrm{H}, \mathrm{d}$, $J=11,0 \mathrm{~Hz}), 4.81(2 \mathrm{H}, \mathrm{s}), 5.15(2 \mathrm{H}, \mathrm{s}), 6.29(1 \mathrm{H}, \mathrm{t}$, $J=7.0 \mathrm{~Hz}), 6.39-6.49(3 \mathrm{H}, \mathrm{m}), 6.64(1 \mathrm{H}, \mathrm{d}, J=8.0$ $\mathrm{Hz}), \quad 6.90 \quad(2 \mathrm{H}, \quad \mathrm{t}, \quad J=7.5 \mathrm{~Hz}), \quad 6.97 \quad(1 \mathrm{H}, \quad \mathrm{t}$, $J=8.0 \mathrm{~Hz}), 7.02(1 \mathrm{H}, \mathrm{t}, J=8.0 \mathrm{~Hz}), 7.09-7.13(2 \mathrm{H}$, $\mathrm{m}), \quad 7.16-7.28\left(17 \mathrm{H}_{\text {arom }}\right), 7.31(2 \mathrm{H}, \mathrm{d}, J=7.5 \mathrm{~Hz})$, $7.37-7.43(3 \mathrm{H}, \mathrm{m}), 7.48(1 \mathrm{H}, \mathrm{d}, J=7.5 \mathrm{~Hz}), 7.52$ $(1 \mathrm{H}, \quad \mathrm{d}, \quad J=7.0 \mathrm{~Hz}), 7.86(1 \mathrm{H}, \quad \mathrm{s}), 7.88(2 \mathrm{H}, \mathrm{d}$, $J=8.0 \mathrm{~Hz}), 8.00(1 \mathrm{H}, \mathrm{s}), 8.39(1 \mathrm{H}, \mathrm{s}) .{ }^{13} \mathrm{C}$ NMR $\left(100 \mathrm{MHz}, \mathrm{CDCl}_{3}\right): 67.4,68.2,71.7,73.5,74.3,75.2$, $75.9\left(\mathrm{CH}_{2}+\mathrm{C}_{6^{\prime}}\right), \quad 70.0, \quad 77.2, \quad 78.0, \quad 81.1, \quad 85.4\left(\mathrm{C}_{1^{\prime}}\right.$, $\left.\mathrm{C}_{2^{\prime}}, \mathrm{C}_{3^{\prime}}, \mathrm{C}_{4^{\prime}}, \mathrm{C}_{5^{\prime}}\right), 111.5,113.5,122.1,123.3,125.1$, $126.9,127.2-129.0,129.5,133.7,134.1,152.1$ (C tert arom), 106.5, 112.9, 120.0, 133.0, 134.6, 136.7, 137.7, $137.8,138.0,151.1,156.4$ (C quat arom), 170.9, $171.2(\mathrm{C}=\mathrm{O})$.

4.1.11. 1-Benzyloxymethyl-3-(1H-indol-3-yl)-4-[7-(2,3,4,6tetra- $O$-benzyl- $\beta$-D-glucopyranos-1-yl)-7 $\mathrm{H}$-pyrrolo[2,3b|pyridin-3-yl|-pyrrole-2,5-dione (19). To a solution of 17 $(223 \mathrm{mg}, 0.201 \mathrm{mmol})$ in THF $(18 \mathrm{~mL})$ was added $1.1 \mathrm{M}$ $n$ - $\mathrm{Bu}_{4} \mathrm{NF}$ in THF $(0.9 \mathrm{~mL})$. The mixture was stirred overnight at room temperature. Water $(45 \mathrm{~mL})$ was added. After extraction with EtOAc, the organic phase was dried over $\mathrm{MgSO}_{4}$, then the solvent was removed and the residue was purified by flash chromatography (eluent: cyclohexane/EtOAc 8:2) to give 19 (109 mg, $0.112 \mathrm{mmol}, 56 \%$ yield) as a red solid.

Mp: $93-95^{\circ} \mathrm{C}$. IR $(\mathrm{KBr}) v_{\mathrm{C}=\mathrm{O}} 1704,1760 \mathrm{~cm}^{-1}, v_{\mathrm{NH}}$ $3406 \mathrm{~cm}^{-1}$. Mass (ESI+) $[\mathrm{M}+\mathrm{H}]^{+}$971. ${ }^{1} \mathrm{H} \quad \mathrm{NMR}$ $\left(400 \mathrm{MHz}, \mathrm{CDCl}_{3}\right): 3.65(1 \mathrm{H}, \mathrm{d}, J=10.0 \mathrm{~Hz}), 3.72$ $3.80(2 \mathrm{H}, \mathrm{m}), 3.80-3.88(2 \mathrm{H}, \mathrm{m}), 3.94(1 \mathrm{H}, \mathrm{t}, J=8.5$ $\mathrm{Hz}), \quad 4.24 \quad(1 \mathrm{H}, \quad \mathrm{d}, \quad J=11.0 \mathrm{~Hz}), \quad 4.44 \quad(1 \mathrm{H}, \quad \mathrm{d}$, $J=12.0 \mathrm{~Hz}), 4.52(1 \mathrm{H}, \mathrm{d}, J=12.0 \mathrm{~Hz}), 4.58(1 \mathrm{H}, \mathrm{d}$, $J=11.0 \mathrm{~Hz}), 4.71(2 \mathrm{H}, \mathrm{s}), 4.80-4.88(3 \mathrm{H}, \mathrm{m}), 5.21$ $(2 \mathrm{H}, \quad \mathrm{s}), \quad 6.41 \quad(1 \mathrm{H}, \quad \mathrm{t}, \quad J=7.5 \mathrm{~Hz}), 6.48 \quad(1 \mathrm{H}, \quad \mathrm{t}$, $J=7.0 \mathrm{~Hz}), 6.53(2 \mathrm{H}, \mathrm{d}, J=8.0 \mathrm{~Hz}), 6.78(1 \mathrm{H}, \mathrm{d}$, $J=8.0 \mathrm{~Hz}), 6.90(1 \mathrm{H}, \mathrm{t}, J=8.0 \mathrm{~Hz}), 6.99(2 \mathrm{H}, \mathrm{t}$, $J=7.5 \mathrm{~Hz}), 7.09(1 \mathrm{H}, \mathrm{t}, J=7.0 \mathrm{~Hz}), 7.13-7.18(2 \mathrm{H}$, $\mathrm{m}), \quad 7.19-7.33\left(20 \mathrm{H}_{\text {arom }}\right), 7.38(2 \mathrm{H}, \mathrm{d}, J=7.5 \mathrm{~Hz})$, $7.57(1 \mathrm{H}, \mathrm{d}, J=6.5 \mathrm{~Hz}), 7.60(1 \mathrm{H}, \mathrm{d}, J=7.5 \mathrm{~Hz})$, $7.77(1 \mathrm{H}, \quad \mathrm{d}, \quad J=2.5 \mathrm{~Hz}), 9.34(1 \mathrm{H}, \quad \mathrm{s}, \quad \mathrm{NH}) .{ }^{13} \mathrm{C}$ NMR $\left(100 \mathrm{MHz}, \mathrm{CDCl}_{3}\right): \quad 67.2, \quad 68.3,71.6,73.5$, $\begin{array}{lllll}74.3, & 75.1, & 75.8 & \left(\mathrm{C}_{6^{\prime}}+\mathrm{CH}_{2}\right), \quad 77.2, \quad 78.1, \quad 81.2, \quad 85.4\end{array}$ $\left(\mathrm{C}_{1^{\prime}}, \mathrm{C}_{2^{\prime}}, \mathrm{C}_{3^{\prime}}, \mathrm{C}_{4^{\prime}}, \mathrm{C}_{5^{\prime}}\right), 110.9,111.5,120.3,121.8$, $122.6,127.5-128.7,133.9,150.7$ (C tert arom), 106.9, $107.1,124.6,125.1,128.8,136.0,136.5,137.8,137.9$, $138.0,138.2,150.6$ (C quat arom), 172.0, 172.1 $(\mathrm{C}=\mathrm{O})$.

4.1.12. 6-Benzyloxymethyl-1-(2,3,4,6-tetra- $O$-benzyl- $\beta$-Dglucopyranos-1-yl)-1 $H$-pyrido $\left[3^{\prime}, 2^{\prime}: 4,5\right]$ pyrrolo $[2,3-a]$ pyrrolo[3,4-c]carbazole-5,7(12H)-dione (21). A mixture of 19 $(70 \mathrm{mg}, 0.072 \mathrm{mmol})$ and iodine $(29 \mathrm{mg}, 0.106 \mathrm{mmol})$ in benzene $(150 \mathrm{~mL})$ was irradiated according to the procedure described for the synthesis of compound 13. After identical work-up, the residue was purified by flash chromatography (eluent: cyclohexane/EtOAc 7:3) to give 21 ( $53 \mathrm{mg}, 0.055 \mathrm{mmol}, 76 \%$ yield) as a yellow solid.

Mp $68-73{ }^{\circ} \mathrm{C}$. IR $(\mathrm{KBr}) v_{\mathrm{C}=\mathrm{O}} 1702,1751 \mathrm{~cm}^{-1}, v_{\mathrm{NH}}$ $3396 \mathrm{~cm}^{-1}$. ${ }^{1} \mathrm{H}$ NMR $\left(400 \mathrm{MHz}, \mathrm{CDCl}_{3}\right): 3.63-3.89$ $(6 \mathrm{H}, \mathrm{m}), 4.28(1 \mathrm{H}, \mathrm{d}, J=11.5 \mathrm{~Hz}), 4.41(1 \mathrm{H}, \mathrm{d}$, $J=12.0 \mathrm{~Hz}), 4.50(1 \mathrm{H}, \mathrm{d}, J=12.0 \mathrm{~Hz}), 4.54(1 \mathrm{H}, \mathrm{d}$, $J=11.0 \mathrm{~Hz}), 4.61-4.68(2 \mathrm{H}, \mathrm{m}), 4.70(2 \mathrm{H}, \mathrm{s}), 4.77$ $(1 \mathrm{H}, \quad \mathrm{d}, \quad J=10.0 \mathrm{~Hz}), \quad 5.25(2 \mathrm{H}, \mathrm{s}), 6.34(2 \mathrm{H}, \mathrm{d}$, $J=7.5 \mathrm{~Hz}), 6.63(2 \mathrm{H}, \mathrm{t}, J=7.0 \mathrm{~Hz}), 7.04-7.32\left(23 \mathrm{H}_{\text {arom }}\right)$, $7.36(2 \mathrm{H}, \mathrm{d}, J=7.5 \mathrm{~Hz}), 7.38-7.42(2 \mathrm{H}, \mathrm{m}), 7.68(1 \mathrm{H}, \mathrm{d}$, $J=6.5 \mathrm{~Hz}), 9.01(1 \mathrm{H}, \mathrm{d}, J=8.0 \mathrm{~Hz}), 9.22(1 \mathrm{H}$, br s $)$, $10.47\left(1 \mathrm{H}\right.$, br s, NH). ${ }^{13} \mathrm{C}$ NMR $\left(100 \mathrm{MHz}, \mathrm{CDCl}_{3}\right)$ : 66.9, 68.3, 71.5, 73.6, 74.5, 75.1, $75.7\left(\mathrm{C}_{6^{\prime}}+\mathrm{CH}_{2}\right), 77.2$, 78.1, 82.0, 85.7 $\left(\mathrm{C}_{1^{\prime}}, \mathrm{C}_{2^{\prime}}, \mathrm{C}_{3^{\prime}}, \mathrm{C}_{4^{\prime}}, \mathrm{C}_{5^{\prime}}\right), 111.5,116.2$, $120.4,120.7,125.3,127.2,127.5-128.5,129.7,132.4$, 136.7 (C tert arom), 115.2, 118.1, 119.4, 119.7, 122.4, 136.3, 137.8, 137.9, 138.1, 140.5 (C quat arom), 169.9, $170.2(\mathrm{C}=\mathrm{O})$.

4.1.13. 1-( $\beta$-D-Glucopyranos-1-yl)-1 $H$-pyrido $\left[3^{\prime}, 2^{\prime}: 4,5\right] p y r-$ rolo[2,3-a]pyrrolo[3,4-c]carbazole-5,7(6H,12H)-dione (23). To a suspension of $21(53 \mathrm{mg}, 0.055 \mathrm{mmol})$ in $\mathrm{CH}_{2} \mathrm{Cl}_{2}(5.5 \mathrm{~mL})$ at $-78^{\circ} \mathrm{C}$ was added $1 \mathrm{M} \mathrm{BBr}_{3}$ in $\mathrm{CH}_{2} \mathrm{Cl}_{2}(1.1 \mathrm{~mL})$. The reaction was carried out as described for the synthesis of compound $\mathbf{2 2}$.

After removal of the solvent, the solid residue was washed with $\mathrm{CH}_{2} \mathrm{Cl}_{2}$ then with water to give $\mathbf{2 3}$ (9.7 mg, $0.020 \mathrm{mmol}, 36 \%$ yield) as a red solid.

$\mathrm{Mp}>200{ }^{\circ} \mathrm{C}$ (decomposition). IR ( $\left.\mathrm{KBr}\right) v_{\mathrm{C}=\mathrm{O}} 1703$, $1743 \mathrm{~cm}^{-1}, \quad v_{\mathrm{NH}} 3004-3654 \mathrm{~cm}^{-1}$. HRMS (FAB+) $[\mathrm{M}+\mathrm{H}]^{+}$calcd for $\mathrm{C}_{25} \mathrm{H}_{20} \mathrm{~N}_{4} \mathrm{O}_{7}$ 489.1410, found 489.1419. ${ }^{1} \mathrm{H}$ NMR (400 MHz, DMSO- $\left.d_{6}\right): 3.46(1 \mathrm{H}$, $\left.\mathrm{m}, \mathrm{H}_{6^{\prime}}\right), 3.52-3.64\left(3 \mathrm{H}, \mathrm{m}, \mathrm{H}_{3^{\prime}}, \mathrm{H}_{5^{\prime}}, \mathrm{H}_{4^{\prime}}\right), 3.84(1 \mathrm{H}, \mathrm{dd}$, $\left.J_{1}=10.5 \mathrm{~Hz}, J_{2}=5.5 \mathrm{~Hz}\right), 3.94\left(1 \mathrm{H}, \mathrm{dt}, J_{1}=9.0 \mathrm{~Hz}\right.$, $\left.J_{2}=5.0 \mathrm{~Hz}, \mathrm{H}_{2^{\prime}}\right), 4.74\left(1 \mathrm{H}, \mathrm{t}, J=6.0 \mathrm{~Hz}, \mathrm{OH}_{6^{\prime}}\right), 5.33$ $\left(1 \mathrm{H}, \mathrm{d}, J=6.0 \mathrm{~Hz}, \mathrm{OH}_{4^{\prime}}\right), 5.46(1 \mathrm{H}, \mathrm{d}, J=4.5 \mathrm{~Hz}$, $\left.\mathrm{OH}_{3^{\prime}}\right), 5.57\left(1 \mathrm{H}, \mathrm{d}, J=5.0 \mathrm{~Hz}, \mathrm{OH}_{2^{\prime}}\right), 6.82(1 \mathrm{H}, \mathrm{d}$, $\left.J=9.5 \mathrm{~Hz}, \mathrm{H}_{1^{\prime}}\right), 7.35(1 \mathrm{H}, \mathrm{t}, J=7.0 \mathrm{~Hz}), 7.39(1 \mathrm{H}, \mathrm{t}$, $J=7.0 \mathrm{~Hz}), 7.55(1 \mathrm{H}, \mathrm{t}, J=7.5 \mathrm{~Hz}), 7.71(1 \mathrm{H}, \mathrm{d}$, $J=8.0 \mathrm{~Hz}), 8.68(1 \mathrm{H}, \mathrm{d}, J=6.5 \mathrm{~Hz}), 9.00(1 \mathrm{H}, \mathrm{d}$, $J=8.0 \mathrm{~Hz}), 9.43(1 \mathrm{H}, \mathrm{d}, J=7.0 \mathrm{~Hz}), 10.94(1 \mathrm{H}$, br s, $\mathrm{NH}), 12.56(1 \mathrm{H}, \mathrm{s}, \mathrm{NH}) .{ }^{13} \mathrm{C} \mathrm{NMR}\left(100 \mathrm{MHz}, \mathrm{CDCl}_{3}\right)$ : $60.9\left(\mathrm{C}_{6^{\prime}}\right), 69.5,72.6,77.2,81.1,86.5\left(\mathrm{C}_{1^{\prime}}, \mathrm{C}_{2^{\prime}}, \mathrm{C}_{3^{\prime}}, \mathrm{C}_{4^{\prime}}\right.$, $\left.\mathrm{C}_{5^{\prime}}\right), 109.8,111.8,119.7,124.2,126.4,132.5,135.7$ (C tert arom), 114.8, 116.0, 119.1, 120.6, 121.7, 124.1, 133.6, 140.7, 142.9, 154.0 (C quat arom), 171.5, 171.7 $(\mathrm{C}=\mathrm{O})$.

4.1.14. 3-(1H-Indol-3-yl)-1-methyl-4-[1-(3,4,6-tri- $O$-benzyl- $\beta$-D-glucopyranos-1-yl)- $1 H$-pyrrolo[2,3-b]pyridin-3yll-pyrrole-2,5-dione (I) and 3-(1 H-indol-3-yl)-4-[7-(3,4, 6-tri- $O$-benzyl- $\beta$-D-glucopyranos-1-yl)-7 $H$-pyrrolo[2,3-b|pyridin-3-yl-1-methyl-pyrrole-2,5-dione (24). To a solution of $3,4,6$-tri- $O$-benzyl-glucal $(280 \mathrm{mg}, \quad 0.680 \mathrm{mmol})$ in $\mathrm{CH}_{2} \mathrm{Cl}_{2}(4 \mathrm{~mL})$ was added at $0{ }^{\circ} \mathrm{C}$ a solution of $0.07-$ $0.09 \mathrm{M}$ dimethyldioxirane in acetone $(15 \mathrm{~mL}) .{ }^{17,18}$ The mixture was stirred at $0^{\circ} \mathrm{C}$ for $40 \mathrm{~min}$. After evaporation under reduced pressure at $0^{\circ} \mathrm{C}$, the residue was dried under vacuum for $2 \mathrm{~h}$. To a solution of aglycone 
A (100 mg, $0.225 \mathrm{mmol})$ in THF $(5 \mathrm{~mL})$ was added $\mathrm{NaH}$ (11.8 $\mathrm{mg}, 60 \%$ dispersion in mineral oil). The mixture was stirred for $30 \mathrm{~min}$ at room temperature before dropwise addition of a solution of $\mathbf{H}$ in THF $(4 \mathrm{~mL})$. After refluxing for $48 \mathrm{~h}$, the solvent was removed and the residue was dried under vacuum for $2 \mathrm{~h}$. The residue was dissolved in formic acid and stirred at room temperature for $24 \mathrm{~h}$. After evaporation, the residue was purified by flash chromatography (eluent: cyclohexane/EtOAc from $7: 3$ to $5: 5)$ to give I ( $34.8 \mathrm{mg}, 0.045 \mathrm{mmol}, 20 \%$ yield) and 24 (111 mg, $0.143 \mathrm{mmol}, 63 \%$ yield) as red solids.

\section{Compound I}

Mp: $72-75^{\circ} \mathrm{C}$. IR $(\mathrm{KBr}), v_{\mathrm{C}=\mathrm{O}} 1700,1751 \mathrm{~cm}^{-1}, v_{\mathrm{NH}, \mathrm{OH}}$ $3300-3500 \mathrm{~cm}^{-1}$. Mass $(\mathrm{FAB}+)[\mathrm{M}+\mathrm{H}]^{+} 775 .{ }^{1} \mathrm{H} \mathrm{NMR}$ $\left(400 \mathrm{MHz}, \mathrm{CDCl}_{3}\right): 3.15\left(3 \mathrm{H}, \mathrm{s}, \mathrm{N}-\mathrm{CH}_{3}\right), 3.65-3.84(5 \mathrm{H}$, $\mathrm{m}), \quad 3.94\left(1 \mathrm{H}, \quad \mathrm{t}, \quad J=9.0 \mathrm{~Hz}, \mathrm{H}_{2^{\prime}}\right), 4.44(1 \mathrm{H}, \quad \mathrm{d}$, $J=12.0 \mathrm{~Hz}), 4.53(1 \mathrm{H}, \mathrm{d}, J=12.0 \mathrm{~Hz}), 4.60(1 \mathrm{H}, \mathrm{d}$, $J=11.0 \mathrm{~Hz}), 4.87(1 \mathrm{H}, \mathrm{d}, J=11.0 \mathrm{~Hz}), 4.89(1 \mathrm{H}, \mathrm{d}$, $J=11.5 \mathrm{~Hz}), 4.94(1 \mathrm{H}, \mathrm{d}, J=11.5 \mathrm{~Hz}), 5.96(1 \mathrm{H}, \mathrm{d}$, $\left.J=9.0 \mathrm{~Hz}, \quad \mathrm{H}_{1^{\prime}}\right), \quad 6.77 \quad(2 \mathrm{H}, \quad \mathrm{m}), 6.95 \quad(1 \mathrm{H}, \quad \mathrm{d}$, $J=8.5 \mathrm{~Hz}), 7.03(1 \mathrm{H}, \mathrm{t}, J=7.5 \mathrm{~Hz}), 7.17-7.43\left(17 \mathrm{H}_{\text {arom }}\right)$, $7.47(1 \mathrm{H}, \mathrm{d}, J=3.0 \mathrm{~Hz}), 7.80(1 \mathrm{H}, \mathrm{s}), 8.21(1 \mathrm{H}, \mathrm{dd}$, $\left.J_{1}=4.5 \mathrm{~Hz}, \quad J_{2}=1.5 \mathrm{~Hz}\right), 9.15(1 \mathrm{H}, \mathrm{d}, J=2.5 \mathrm{~Hz}$, $\left.\mathrm{NH}_{\text {ind }}\right) .{ }^{13} \mathrm{C}$ NMR $\left(100 \mathrm{MHz}, \mathrm{CDCl}_{3}\right): 24.2\left(\mathrm{~N}-\mathrm{CH}_{3}\right)$, 68.6 $\left(\mathrm{C}_{6^{\prime}}\right), 73.5,75.0,75.5\left(\mathrm{CH}_{2}\right.$ of $\left.\mathrm{OBn}\right), 73.6,77.4$, 77.6, 82.9, 85.5 $\left(\mathrm{C}_{1^{\prime}}, \mathrm{C}_{2^{\prime}}, \mathrm{C}_{3^{\prime}}, \mathrm{C}_{4^{\prime}}, \mathrm{C}_{5^{\prime}}\right), 111.8,117.2$, $120.4,121.9,122.7,127.5-128.7,129.2,130.9,142.0$, 143.7 (C tert arom), 106.3, 118.9, 124.7, 126.0, 129.1, $136.1,137.9,138.1,138.6,148.0$ (C quat arom), 172.0 $(2 \mathrm{C}, \mathrm{C}=\mathrm{O})$.

\section{Compound 24}

Mp: $\quad 92-95^{\circ} \mathrm{C}$. IR $(\mathrm{KBr}) \quad v_{\mathrm{C}=\mathrm{O}} \quad 1690,1750 \mathrm{~cm}^{-1}$, $v_{\mathrm{NH}, \mathrm{OH}} \quad 3200-3600 \mathrm{~cm}^{-1}$. HRMS (ESI+) $[\mathrm{M}+\mathrm{H}]^{+}$ calcd for $\mathrm{C}_{47} \mathrm{H}_{43} \mathrm{~N}_{4} \mathrm{O}_{7} 775.3132$, found 775.3115 . ${ }^{1} \mathrm{H}$ NMR $\left(400 \mathrm{MHz}, \mathrm{CDCl}_{3}\right): 3.08\left(3 \mathrm{H}, \mathrm{s}, \mathrm{N}-\mathrm{CH}_{3}\right)$, $3.64-3.88(6 \mathrm{H}, \mathrm{m}), 4.42(1 \mathrm{H}, \mathrm{d}, J=12.0 \mathrm{~Hz}), 4.48$ $(1 \mathrm{H}, \mathrm{d}, J=12.0 \mathrm{~Hz}), 4.51(1 \mathrm{H}, \mathrm{d}, J=11.0 \mathrm{~Hz}), 4.79$ $(1 \mathrm{H}, \mathrm{d}, J=11.0 \mathrm{~Hz}), 4.80(1 \mathrm{H}, \mathrm{d}, J=11.0 \mathrm{~Hz}), 4.91$ $(1 \mathrm{H}, \mathrm{d}, J=11.0 \mathrm{~Hz}), 6.53\left(1 \mathrm{H}, \mathrm{d}, J=9.0 \mathrm{~Hz}, \mathrm{H}_{1^{\prime}}\right)$, $6.62-6.74(3 \mathrm{H}, \mathrm{m}), 6.97\left(1 \mathrm{H}, \quad \mathrm{dt}, \quad J_{1}=8.0 \mathrm{~Hz}\right.$, $\left.J_{2}=1.5 \mathrm{~Hz}\right), 7.10-7.14(2 \mathrm{H}, \mathrm{m}), 7.19-7.30\left(14 \mathrm{H}_{\text {arom }}\right)$, $7.63(1 \mathrm{H}, \mathrm{d}, J=2.5 \mathrm{~Hz}), 7.67(1 \mathrm{H}, \mathrm{d}, J=7.5 \mathrm{~Hz})$, $7.83(1 \mathrm{H}, \mathrm{d}, J=6.0 \mathrm{~Hz}), 8.11(1 \mathrm{H}, \mathrm{s}), 9.10(1 \mathrm{H}, \mathrm{s}$, $\left.\mathrm{NH}_{\text {ind }}\right) .{ }^{13} \mathrm{C}$ NMR $\left(100 \mathrm{MHz}, \mathrm{CDCl}_{3}\right): 24.1\left(\mathrm{~N}-\mathrm{CH}_{3}\right)$, $68.4\left(\mathrm{C}_{6^{\prime}}\right), 73.4,74.9,75.5\left(\mathrm{CH}_{2}\right.$ of $\left.\mathrm{OBn}\right), 76.3,76.6$, 78.2, 85.7, 86.8 $\left(\mathrm{C}_{1^{\prime}}, \mathrm{C}_{2^{\prime}}, \mathrm{C}_{3^{\prime}}, \mathrm{C}_{4^{\prime}}, \mathrm{C}_{5^{\prime}}\right), 111.1,111.5$, $120.3,121.8,122.4,126.0,127.7-128.4,134.4,148.9$ (C tert arom), 106.7, 107.2, 124.9, 125.2, 127.5, 128.1, $136.0,137.7,137.9,138.4,150.2$ (C quat arom), $172.6,172.7(\mathrm{C}=\mathrm{O})$.

4.1.15. 1-(3,4,6-Tri-O-benzyl- $\beta$-D-glucopyranos-1-yl)-6methyl-1 $H$-pyrido[3',2' 4 ,5]pyrrolo[2,3-a]pyrrolo[3,4-c]carbazole-5,7(12H)-dione (25). A mixture of $24(100 \mathrm{mg}$, $0.129 \mathrm{mmol}$ ) and iodine (388 mg, $1.52 \mathrm{mmol}$ ) in benzene $(150 \mathrm{~mL})$ was irradiated as described for the synthesis of compound 13. After identical work-up, the residue was purified by flash chromatography (eluent: EtOAc/cyclohexane from $5: 5$ to $8: 2)$ to give $\mathbf{2 5}$ (68 $\mathrm{mg}, 0.088 \mathrm{mmol}$,
$69 \%$ yield) as a yellow solid. Mp: $237-240{ }^{\circ} \mathrm{C}$ (decomposition). IR (KBr) $v_{\mathrm{C}=\mathrm{O}} 1690,1745 \mathrm{~cm}^{-1}, v_{\mathrm{NH}, \mathrm{OH}} 3200$ $3600 \mathrm{~cm}^{-1}$. HRMS (FAB +$) \quad[\mathrm{M}+\mathrm{H}]^{+}$calcd for $\mathrm{C}_{47} \mathrm{H}_{41} \mathrm{~N}_{4} \mathrm{O}_{7}$ 773.2975, found 773.2956. ${ }^{1} \mathrm{H}$ NMR $\left(400 \mathrm{MHz}, \mathrm{CDCl}_{3}\right): 3.18\left(3 \mathrm{H}, \mathrm{s}, \mathrm{N}-\mathrm{CH}_{3}\right), 3.72-3.86$ $(5 \mathrm{H}, \mathrm{m}), 3.90(1 \mathrm{H}, \mathrm{m}), 4.47(1 \mathrm{H}, \mathrm{d}, J=12.5 \mathrm{~Hz}), 4.54$ $(1 \mathrm{H}, \mathrm{d}, J=12.0 \mathrm{~Hz}), 4.63(1 \mathrm{H}, \mathrm{d}, J=10.5 \mathrm{~Hz}), 4.85$ $(1 \mathrm{H}, \mathrm{d}, J=11.0 \mathrm{~Hz}), 4.87(1 \mathrm{H}, \mathrm{d}, J=11.0 \mathrm{~Hz}), 5.02$ $(1 \mathrm{H}, \mathrm{d}, J=11.5 \mathrm{~Hz}), 5.93(1 \mathrm{H}, \mathrm{d}, J=6.0 \mathrm{~Hz}, \mathrm{OH})$, $6.81\left(1 \mathrm{H}, \mathrm{d}, J=9.5 \mathrm{~Hz}, \mathrm{H}_{1^{\prime}}\right), 7.20-7.38\left(15 \mathrm{H}_{\text {arom }}\right), 7.41$ $(2 \mathrm{H}, \mathrm{t}, J=7.0 \mathrm{~Hz}), 7.52\left(1 \mathrm{H}, \mathrm{dt}, J_{1}=8.0 \mathrm{~Hz}, J_{2}=\right.$ $1.0 \mathrm{~Hz}), 7.69(1 \mathrm{H}, \quad \mathrm{d}, \quad J=8.0 \mathrm{~Hz}), 8.74(1 \mathrm{H}, \quad \mathrm{d}$, $J=6.0 \mathrm{~Hz}), 8.98(1 \mathrm{H}, \mathrm{d}, J=8.0 \mathrm{~Hz}), 9.43(1 \mathrm{H}, \mathrm{dd}$, $\left.J_{1}=7.5 \mathrm{~Hz}, J_{2}=1.0 \mathrm{~Hz}\right), 12.50\left(1 \mathrm{H}, \mathrm{s}, \mathrm{NH}_{\text {ind }}\right) .{ }^{13} \mathrm{C}$ NMR $\left(100 \mathrm{MHz}, \mathrm{CDCl}_{3}\right): 23.5\left(\mathrm{~N}-\mathrm{CH}_{3}\right), 68.5\left(\mathrm{C}_{6^{\prime}}\right)$, 72.3, 74.3, $74.4\left(\mathrm{CH}_{2}\right.$ of $\left.\mathrm{OBn}\right), 72.7,76.7,77.7,85.2$, $86.8\left(\mathrm{C}_{1^{\prime}}, \mathrm{C}_{2^{\prime}}, \mathrm{C}_{3^{\prime}}, \mathrm{C}_{4^{\prime}}, \mathrm{C}_{5^{\prime}}\right), 109.9,111.9,119.8,124.0$, $126.5,127.3-128.3,132.3,135.8$ (C tert arom), 115.0, $116.2,118.2,119.6,121.6,124.3,133.5,137.9,138.0$, $138.8,140.9,142.7,154.1$ (C quat arom), 170.2, 170.3 $(\mathrm{C}=\mathrm{O})$.

\subsection{Melting temperature studies}

The concentrations of CT-DNA and double stranded poly(dAdT) oligonucleotide (Sigma-Aldrich) were determined from their molar extinction coefficients of $6600 \mathrm{M}^{-1} \mathrm{~cm}^{-1}$. Compounds 14 and 22, NB-506, and camptothecin (Sigma) were prepared in DMSO $(10 \mathrm{mM})$ and more diluted solutions were freshly prepared in the appropriate experimental buffers.

CT-DNA or poly $(\mathrm{dAdT})_{2}(20 \mu \mathrm{M})$ was incubated with increasing concentrations of compounds 14 or 22 in $1 \mathrm{~mL}$ of BPE buffer for a final drug/base pair ratio of $0.1,0.25,0.5$ or 1 . The absorbency at $260 \mathrm{~nm}$ was measured using an Uvikon 943 spectrophotometer thermostated with a Neslab RTE111 cryostat with a point measured every min over a range of $20-100{ }^{\circ} \mathrm{C}$ with an increment of $1^{\circ} \mathrm{C}$ per min. The $T_{\mathrm{m}}$ values were deduced from the midpoint of the hyperchromic transition and the variation of melting temperature $\left(\Delta T_{\mathrm{m}}\right)$ calculated from the formula : $\Delta T_{\mathrm{m}}=T_{\mathrm{m} \text { [drug+DNA }]}-T_{\mathrm{m} \text { [DNA alone }]}$.

\subsection{Topoisomerase I-mediated DNA cleavage}

Graded concentrations of compounds 14, 22, NB506 or $20 \mu \mathrm{M}$ of CPT were incubated with supercoiled pUC19 plasmid DNA (120 ng) or 117 base pairs $3^{\prime}$ end-labeled DNA fragments in $20 \mu \mathrm{L}$ of relaxation buffer for $15 \mathrm{~min}$ at $37^{\circ} \mathrm{C}$ to ensure binding equilibrium prior to adding human recombinant topoisomerase I enzyme $(4 \mathrm{U})$ for a further $30 \mathrm{~min}$ incubation at $37^{\circ} \mathrm{C}$. The cleavage reactions were then stopped through digestion of the topoisomerase I protein by adding SDS $(0.25 \%)$ and proteinase $\mathrm{K}(250 \mu \mathrm{g} / \mathrm{mL})$ for $30 \mathrm{~min}$ at $50^{\circ} \mathrm{C}$. The DNA samples were then differently separated depending on the size of the various DNA substrates. On the one hand, the plasmid DNA samples were loaded onto a $1 \%$ agarose ethidium bromide-containing gel after addition of $2 \mu \mathrm{L}$ of the loading buffer. After a $2 \mathrm{~h}$ electrophoresis in TBE buffer at $120 \mathrm{~V}$ at room temperature, the 
agarose gel was photographed under UV light. On the other hand, the radiolabeled DNA samples were precipitated to be then diluted in $5 \mu \mathrm{L}$ of denaturing loading buffer. The samples were heated at $90{ }^{\circ} \mathrm{C}$ for $3 \mathrm{~min}$ and subsequently cooled on ice to then be separated on a $8 \%$ denaturing polyacrylamide gel for $90 \mathrm{~min}$ at $65 \mathrm{~W}$ in TBE buffer. The cleaved bands were identified using the Molecular Dynamics 445SI PhosphorImager. The precise localization of the bases on the DNA fragment was established from comparison with the position of guanines in the G-track lane obtained from Maxam and Gilbert classical procedure.

\subsection{Growth inhibition assays}

Tumor cells were provided by American Type Culture Collection (Frederik, MD, USA). They were cultivated in RPMI 1640 medium (Life Science technologies, Cergy-Pontoise, France) supplemented with $10 \%$ fetal calf serum, $2 \mathrm{mM}$ L-glutamine, $100 \mathrm{U} / \mathrm{mL}$ penicillin, $100 \mu \mathrm{g} / \mathrm{mL}$ streptomycin, and $10 \mathrm{mM}$ Hepes buffer $(\mathrm{pH}$ $7.4)$. Cytotoxicity was measured by the microculture tetrazolium assay as described. ${ }^{21}$ Cells were continuously exposed to graded concentrations of the compounds for four doubling times, then $15 \mu \mathrm{L}$ of $5 \mathrm{mg} / \mathrm{mL} 3-(4,5-$ dimethylthiazol-2-yl)-2,5-diphenyltetrazolium bromide was added to each well and the plates were incubated for $4 \mathrm{~h}$ at $37^{\circ} \mathrm{C}$. The medium was then aspirated and the formazan solubilized by $100 \mu \mathrm{L}$ DMSO. Results are expressed as $\mathrm{IC}_{50}$, concentration which reduced by $50 \%$ the optical density of treated cells with respect to untreated controls.

\subsection{Chk1 inhibitory assays}

Human Chk1 full-length enzyme with an N-terminal GST sequence was purchased from Upstate Biochemicals (No. 14-346). Assays for compound testing were based upon the method described by Davies et al. $^{22}$ except that the final ATP concentration was $15 \mu \mathrm{M}$. Compounds $(10 \mu \mathrm{M}$ final concentration) were tested in duplicate and the average inhibition was calculated as a \% relative to samples without compound. The reproducibility of assays was monitored by testing a control compound in every experiment.

\section{Acknowledgments}

We thank the Institut de Recherche sur la Cancer de Lille and the Conseil Régional Nord-Pas-de-Calais for a PhD fellowship to Paul Peixoto and Brigitte Baldeyrou for technical expertise. This work was supported by grants from the Ligue contre le Cancer, Comité du Nord ( $\mathrm{N}^{\circ} 1$ FI3558FEAR).

\section{References and notes}

1. Prudhomme, M. Curr. Med. Chem. 2000, 7, 1189-1212.

2. Long, B. H.; Rose, W. C.; Vyas, D. M.; Matson, J. A.; Forenza, S. Curr. Med. Chem. AntiCancer Agents 2002, 2 , 255-266.

3. Prudhomme, M. Eur. J. Med. Chem. 2003, 38, 123-140.

4. Balasubramanian, B. N.; St. Laurent, D. R.; Saulnier, M. G.; Long, B. H.; Bachand, C.; Beaulieu, F.; Clarke, W.; Deshpande, M.; Eummer, J.; Fairchild, C. R.; Frennesson, D. B.; Kramer, R.; Lee, F. Y.; Mahler, M.; Martel, A.; Narasimhulu Naidu, B.; Rose, W. C.; Russell, J.; Ruediger, E.; Solomon, C.; Stoffan, K. M.; Wong, H.; Zimmermann, K.; Vyas, D. M. J. Med. Chem. 2004, 47, 1609-1612.

5. Prudhomme, M. Curr. Med. Chem. AntiCancer Agents 2004, 4, 509-521.

6. Marminon, C.; Pierré, A.; Pfeiffer, B.; Pérez, V.; Léonce, S.; Joubert, A.; Bailly, C.; Renard, P.; Hickman, J.; Prudhomme, M. J. Med. Chem. 2003, 46, 609-622.

7. Marminon, C.; Pierré, A.; Pfeiffer, B.; Pérez, V.; Léonce, S.; Renard, P.; Prudhomme, M. Bioorg. Med. Chem. 2003, $11,679-687$

8. Messaoudi, S.; Anizon, F.; Léonce, S.; Pierré, A.; Pfeiffer, B.; Prudhomme, M. Eur. J. Med. Chem. 2005, 40, 961971.

9. Mente, S.; Maroncelli, M. J. Phys. Chem. A 1998, 102, $3860-3876$.

10. Mérour, J. Y.; Joseph, B. Curr. Org. Chem. 2001, 5, 471506

11. Zhao, B.; Bower, M. J.; McDevitt, P. J.; Zhao, H.; Davis, S. T.; Johanson, K. O.; Green, S. M.; Concha, N. O.; Zhou, B. B. S. J. Biol. Chem. 2002, 277, 46609-46615.

12. Routier, S.; Coudert, G.; Mérour, J. Y.; Caignard, D. H. Tetrahedron Lett. 2002, 43, 2561-2564.

13. Rodrigues Pereira, E.; Belin, L.; Sancelme, M.; Prudhomme, M.; Ollier, M.; Rapp, M.; Sevère, D.; Riou, J.-F.; Fabbro, D.; Meyer, T. J. Med. Chem. 1996, 39, 4471-4477.

14. Messaoudi, S.; Anizon, F.; Pfeiffer, B.; Prudhomme, M. Tetrahedron 2005, 61, 7304-7316.

15. Ward, D. E.; Gai, Y.; Kaller, B. F. J. Org. Chem. 1995, 60, $7830-7836$

16. Gallant, M.; Link, J. T.; Danishefsky, S. J. J. Org. Chem. 1993, 58, 343-349.

17. Murray, R. W.; Singh, M. Org. Synth. 1997, 74, 91-97.

18. Bovin, N. V.; Zurabyan, S. E.; Khorlin, A. Y. Carbohydr. Res. 1981, 98, 25-35.

19. Prudhomme, M. Curr. Med. Chem. AntiCancer Agents 2004, 4, 435-438.

20. Jiang, X.; Zhao, B.; Britton, R.; Lim, L. Y.; Leong, D.; Sanghera, J. S.; Zhou, B. B. S.; Piers, E.; Andersen, R. J.; Roberge, M. Mol. Cancer Ther. 2004, 3, 1221-1227.

21. Léonce, S.; Pérez, V.; Casabianca-Pignède, M. R.; Anstett, M.; Bisagni, E.; Atassi, G. Invest. New Drugs 1996, 14 , $169-180$.

22. Davies, S. P.; Reddy, H.; Caivano, M.; Cohen, P. Biochem. J. 2000, 351, 95-105. 